\title{
Arc Fusion Splicing of Photonic Crystal Fibres
}

\author{
Krzysztof Borzycki ${ }^{1}$ and Kay Schuster ${ }^{2}$ \\ ${ }^{1}$ National Institute of Telecommunications (NIT) \\ 2Institute of Photonic Technology (IPHT) \\ ${ }^{1}$ Poland \\ ${ }^{2}$ Germany
}

\section{Introduction}

Arc fusion splicing is an established method for joining optical fibres in communication networks, ensuring splice loss down to $0.05 \mathrm{~dB}$ and excellent reliability. Telecom fibres are covered by IEC 60793 and ITU-T G.651.1-G.657 standards, with common material (fused silica) and cladding size $(125 \mu \mathrm{m})$. Splicing equipment for these fibres is widely available.

Fusion splicing of specialty fibres, like dispersion compensating fibres (DCF), polarizationmaintaining fibres (PMF), rare-earth doped active fibres and photonic crystal fibres (PCF) having varying, not standardized designs, dimensions and materials is considerably more difficult. Some, like PMF and many PCFs lack axial symmetry, requiring rotational alignment before fusion. However, this functionality is not available in common splicing machines. A length of specialty fiber enclosed inside a device like optical amplifier, sensor or dispersion compensator is usually spliced at both ends to telecom single mode fibres (SMF) for connections to other components and external interfaces.

Splicing procedure must be tailored to particular fibre, often in a time-consuming trial-anderror way. Special solutions, like fiber pre-forming or insertion of intermediate fiber are sometimes needed. Dedicated splicing machines for such fibres employing both arc fusion (OFS, 2008) and hot filament methods (Vytran, 2009) exist, but are expensive.

Fusion splicing of photonic crystal or other "holey" fibres with numerous tiny, ca. 0.5-4 $\mu \mathrm{m}$ gas-filled holes is particularly hard because holes collapse quickly once glass is heated to melt; this disturbs radiation guiding, introduces loss and causes fiber shrinkage.

There is a need to splice "holey" or "microstructured" fibres for characterization and experiments using typical tools and equipment. PCF-SMF splices are most common, as PCFs need to be connected to test instruments, optical devices and circuits incorporating or designed for SMFs. Splicing PCF to a SMF requires special fiber handling and machine settings different from splicing SMF to SMF, like reduced arc power and fusion time shortened to 0.2-0.5 s. More difficult splicing of two lengths of PCF is much less common.

Fusion splicing has the advantage of gas-tight sealing a length of PCF, which is of importance in making gas-filled absorption cells or protecting the fibre against penetration of humidity, dust or vapours in hostile operating environment. 
This chapter focuses on procedures and experiences with fusion splicing using equipment and tools intended for standard single mode and multimode telecom fibres, which gave acceptable results for most, but not all PCFs the authors encountered. Before this matter is presented in section 4, overview of "holey" fibres and their properties is made in section 2, and arc fusion physics and technology are summarized in section 3.

\section{Microstructured optical fibres}

Their common feature is substantial modification of optical characteristics by presence of multitude of longitudinal holes or concentric layer(s) of solid micro- or nano-particles around the light guiding core. There are several variants, including:

a. PCFs without doped core, e.g. suspended-core and highly birefringent fibres.

b. PCFs with doped core surrounded by layers of holes, like HAF and nonlinear fibres. The core is capable of guiding light on its own.

c. Fibres with solid nanostructured barrier around doped core.

d. Fibres with single central hole surrounded by dielectric mirror (hollow fibers and Photonic Bandgap Fibres).

Bending-tolerant Hole-Assisted Fibres (HAF) and fibres with solid nanostructured barrier found use in optical access networks (FTTH) and are covered by ITU-T G.657 recommendation, specifying their properties - but not designs. Corning ClearCurve fibre with layer of embedded solid particles around core is fusion spliced as SMF, while HAF is converted to SMF by collapse of holes on fusion splicer (Nakajima et al., 2003); both are not covered here. Properties differ: while fibres (b) and (c) are "splicing friendly", work with suspended-core PCFs and other fibres from group (a) is more difficult. Large-core "dielectric mirror" fibres for delivery of high-power laser radiation (d) are used in short lengths and not spliced. Experience of authors applies to first two groups, but recommendations are applicable to most other microstructured fibres. Key properties for fusion splicing include:

- Photonic structure - size and number of holes,

- Radiation-guiding mechanism and its expected disruption by fusion,

- Cladding diameter and protective coating.

\section{Physics and technology of arc fusion splicing}

This section will introduce reader to arc fusion splicing of conventional, solid fibres and techniques adopted for splicing fibres in communication networks.

\subsection{Process basics and physics}

Fusion splicing involves localized melting of two fibre butts pressed together, with fibre coating removed. Surface tension forces cause glass to flow when viscosity is low enough, forming a joint with continuous structure and smooth, round external surface (Figure 1).

While smoothing of edges improves splice strength, self-centring of fibres shown in Figure 2 is undesirable when lateral shift is needed to align non-concentric fibre cores. 


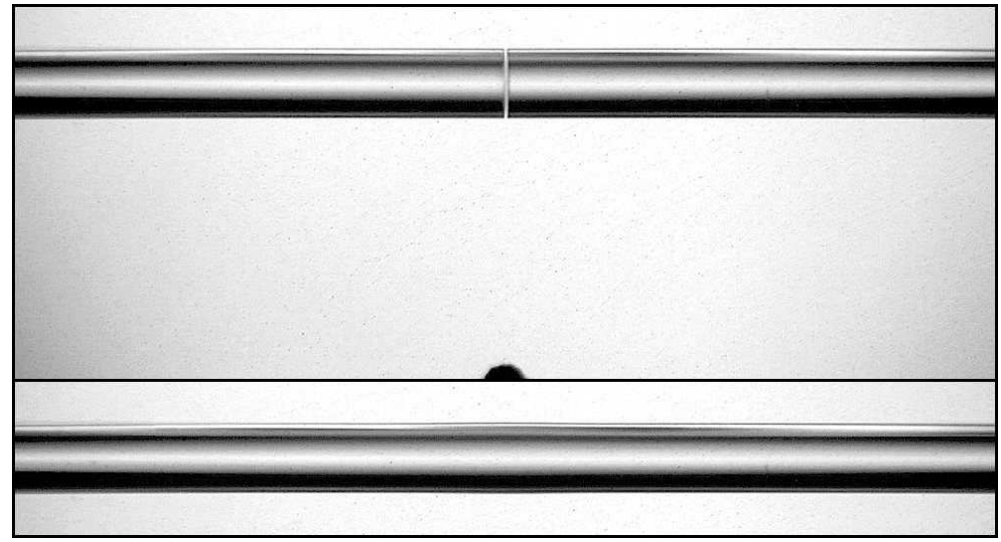

Fig. 1. Two identical $125 \mu \mathrm{m}$ silica fibres before (top) and after (bottom) arc fusion. Electrode tip is visible as a black spot at the bottom of upper image.

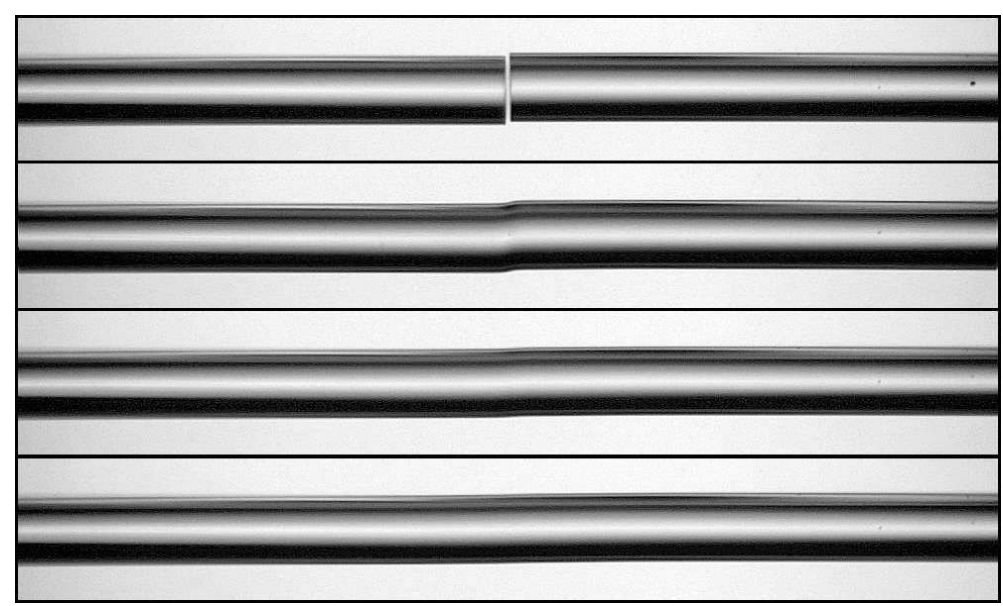

Fig. 2. Two $125 \mu \mathrm{m}$ single-mode fibres spliced with $10 \mu \mathrm{m}$ perpendicular offset. Top to bottom: fibres before fusion and after $0.5 \mathrm{~s}, 1 \mathrm{~s}$ and $2 \mathrm{~s}$ long fusion with $17 \mathrm{~mA}$ current.

Glass evaporating from the hot zone is partly deposited on fibres in the vicinity - degrading surface quality and strength, and on parts of splicing machine - contaminating them. Evaporation is compensated for by fibre overlap: a reduced volume of glass is accommodated in shorter length of fibre without change in diameter. As no air, gel, glue etc. separates fibres after fusion, strength close to one of pristine fibre, no reflection and low insertion loss are possible. The heat for fusion is provided by either:

- external electric discharge (arc fusion splicing),

- resistance heater located close to fibres (filament splicing),

- hydrogen / oxygen burner (flame splicing), or

- $\mathrm{CO}_{2}$ laser radiation absorbed by the fibres (laser splicing). 
The first method is preferred due to compact equipment, fast operation and flexible control. Filament splicing is used for specialty fibres and when high splice strength is required. Other techniques are rarely used. Descriptions below cover arc fusion splicing only.

\subsection{Fused silica properties and fusion splicing}

Fused silica is a glassy form of silicon dioxide $\left(\mathrm{SiO}_{2}\right)$. In comparison to most multicomponent glasses, fused silica exhibits relatively slow decrease of viscosity with temperature (Figure 3). For fusion splicing, this property is desirable, as larger variations in temperature can be tolerated.

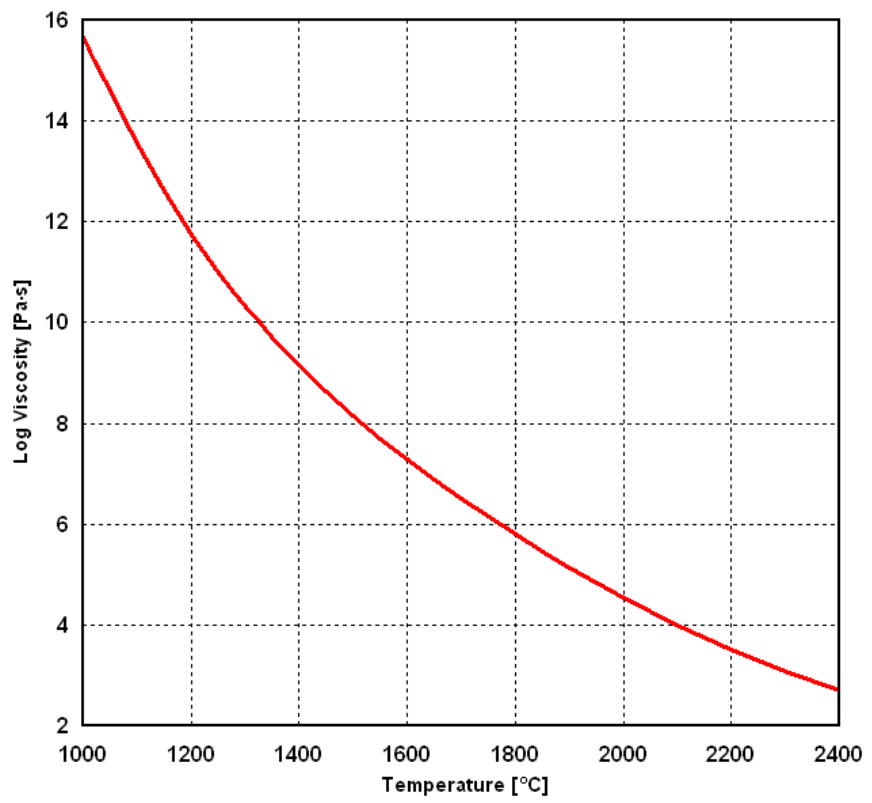

Fig. 3. Viscosity of pure fused silica as function of temperature. Approximate data compiled from sources not in full agreement (Shand, 1968, Yablon, 2005, Schott, 2007).

To ensure fusion in $0.5-2 \mathrm{~s}$, glass viscosity must be reduced to about $10^{4} \mathrm{~Pa}-\mathrm{s}$. Temperatures during different stages of fusion splicing range approximately from $1500^{\circ} \mathrm{C}$ (softening of fibres) to $2100^{\circ} \mathrm{C}$ (fusion), and electric power required to fuse two $125 \mu \mathrm{m}$ solid silica fibres is about 8-10 W. As voltage drop between electrodes is almost constant, 500-600 V for $1 \mathrm{~mm}$ gap, discharge power is essentially proportional to arc current. The range for work with $125 \mu \mathrm{m}$ fibres is approximately 7-20 mA.

Glass melting during fusion of $125 \mu \mathrm{m}$ fibres takes place in zone $0.5-1 \mathrm{~mm}$ long, including effects of distribution of energy inside arc column, which is approx. $0.2 \mathrm{~mm}$ wide for $1 \mathrm{~mm}$ electrode gap. Because fused silica has exceptionally low linear thermal expansion coefficient and heat conductivity, as shown in Table 1, fibre strain during post-fusion cooling from the annealing temperature of approx. $1100^{\circ} \mathrm{C}$ to room temperature is negligible: only $0.0099 \%$ for a $1 \mathrm{~mm}$ hot zone and $6 \mathrm{~mm}$ fibre length between clamps. 


\begin{tabular}{|l|c|c|}
\hline Material & CTE $\left(10^{-6} / \mathrm{K}^{-1}\right)$ & Heat conductivity $(\mathrm{W} / \mathrm{m} \bullet \mathrm{K})$ \\
\hline Fused silica & 0.55 & 1.38 \\
\hline Tungsten & 4.3 & 173 \\
\hline Steel & $13-18$ & $12-45$ \\
\hline Copper & 16.6 & 401 \\
\hline Aluminium & 22.2 & 237 \\
\hline PVC (hard) & $50-80$ & $0.13-0.29$ \\
\hline PET & $60-70$ & $0.17-0.24$ \\
\hline PMMA & $50-90$ & $0.17-0.25$ \\
\hline
\end{tabular}

Table 1. Comparison of thermal properties of fused silica and selected other materials.

Heat transfer during fusion is mostly through bulk radiation at wavelengths of $0.6-2 \mu \mathrm{m}$, to which the glass is transparent, and conduction along the fibre (Yablon, 2005), and:

- temperature inside fibre is essentially independent of radial position,

- such equilibrium is reached after approx. $10 \mathrm{ms,}$

- $\quad$ power needed to reach given temperature is proportional to fibre diameter,

- thermal time constant of $125 \mu \mathrm{m}$ fibres is in order of few tenths of a second.

Doping with germania $\left(\mathrm{GeO}_{2}\right)$ or titania $\left(\mathrm{TiO}_{2}\right)$ considerably reduces silica viscosity, and fusing multimode fibres with 50-62.5 $\mu \mathrm{m}$ core taking $20-25 \%$ of cross-section requires lower temperature than single-mode fibres, where core is small $(4-10 \mu \mathrm{m})$ and contains less $\mathrm{GeO}_{2}$.

In a hot fibre, diffusion of dopant(s) is observed, changing refractive profile and core size. The problem is acute during splicing of "depressed cladding" or "pure silica core" singlemode fibres, where core is surrounded by a layer doped with fluorine (F), a light element easily diffusing at high temperatures; careful control of arc power and short fusion time are required.

Out-gassing of boron, phosphorus, germanium or fluorine compounds from melted glass may cause problems as well, in particular during splicing of highly-doped specialty fibres.

Silica does not burn, decompose or oxidise when heated in the air. However, exposure to humidity, alkalis or sharp objects produces surface flaws; damaged fibre breaks easily. All lengths of fibre stripped of coating must be promptly protected against humidity, abrasion, etc. Only splices intended for short-term use in laboratory conditions may be exempted.

Fusion of fibres with different dopants or doping levels can produce significant internal stress due to uneven thermal contraction after fusion, potentially affecting splice strength.

\subsection{Fusion procedure}

Arc fusion splicing of two single, polymer-coated, multimode or single-mode silica fibres of $125 \mu \mathrm{m}$ cladding diameter usually includes steps listed below:

1. removal of coating from fibres, usually by mechanical stripping,

2. fibre cleaning with solvent: isopropyl alcohol, acetone, etc. or dry wiping,

3. fibre cleaving by scoring with a blade and applying controlled strain till it breaks ("scribe and load"); cleave angle shall be less than $1^{\circ}$,

4. clamping of fibres in supports with V-grooves, 
5. cleaning of fibres by short (0.2-0.5 s), low power electric arc,

6. visual inspection of fibre tips for proper cleave and cleanliness,

7. placing fibre tips between electrodes with $10-20 \mu \mathrm{m}$ gap (butt coupling),

8. alignment of fibres for lowest transmission loss; this may involve application of perpendicular offset with monitoring of loss or observation of cladding or cores,

9. softening of fibres by low power discharge: 6-9 $\mathrm{mA}$ current, 0.5-3 s duration, than pressing together with 6-15 $\mu$ m overlap,

10. fusion of fibres by high power electric arc: $12-20 \mathrm{~mA}$ current, $0.5-2 \mathrm{~s}$ duration,

11. annealing / polishing of fibres with low power electric arc (optional),

12. visual inspection of splice: no distortions, slits or bubbles allowed,

13. insertion loss measurement (optional),

14. tensile strength test (optional),

15. splice protection by heat-shrinkable sleeve, re-coating, etc.

Figure 4 shows typical sequence of arc current and fibre movement.
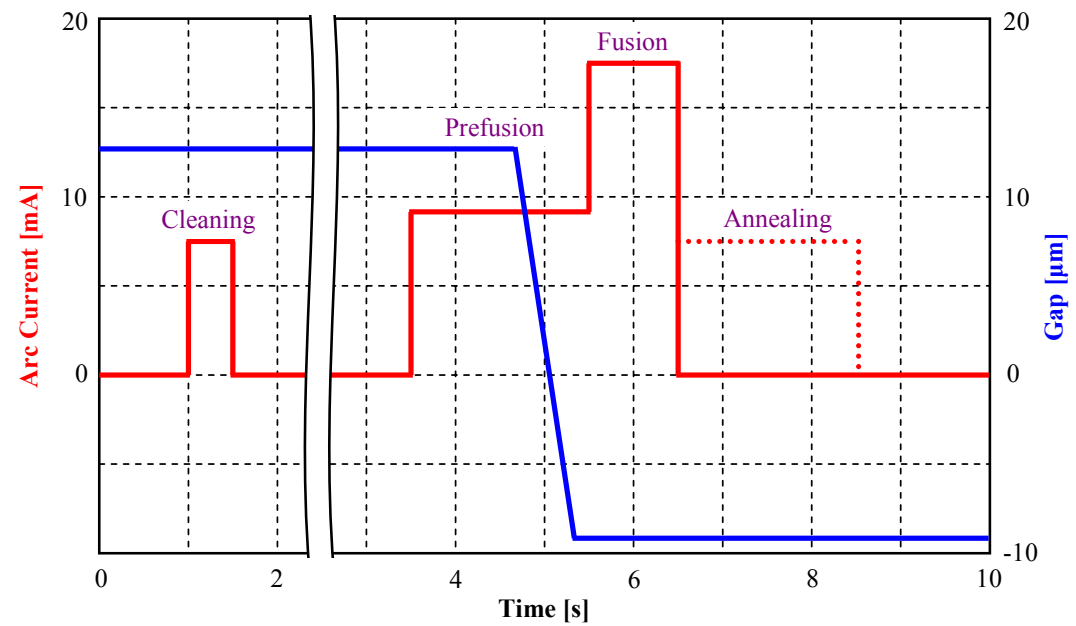

Fig. 4. Example of fibre-fibre gap and arc current variations during fusion splicing of SMF. Negative value of gap means an overlap of fibres pressed into each other.

Arc current and duration of heating in steps 9-11 and fibre overlap in step 9 depend on fibres spliced. $10 \%$ deviation from optimum arc current is usually enough to significantly rise splice loss or reduce splice strength, if current and temperature are too low. To reduce self-centring, fusion time is shorter for single mode than multimode fibres: $0.5-1$ s vs. $1-2 \mathrm{~s}$.

Some coatings require thermal stripping, softening with chemicals or burning for removal. When high splice strength is required, acrylate, epoxy-acrylate or polyimide coatings can be dissolved during 20-30 s immersion in hot $\left(180-200^{\circ} \mathrm{C}\right)$ sulphuric acid $\left(\mathrm{H}_{2} \mathrm{SO}_{4}\right)$ - either pure $(\geq 95 \%)$ or with addition of approx. $5 \%$ nitric acid $\left(\mathrm{HNO}_{3}\right)$. Residual acid is removed by rinsing the fibre with water and later acetone (Matthewson et al., 1997). 


\subsection{Fibre alignment and splice loss}

Fibre core guiding radiation is small, with effective diameter usually in the 2-15 $\mu \mathrm{m}$ range in single-mode fibres, with extreme values often encountered in PCFs, and accurate alignment of fibre cores during splicing is essential. Main factors introducing splice loss include:

- mismatch between core sizes, characterized by mode field diameter (MFD) in singlemode fibres and physical core diameter in multimode fibres,

- lateral offset between fibre cores,

- angular misalignment of fibres,

- mismatch in numerical aperture (NA) of multimode fibres,

- distortions of splice, e.g. due to poor cleaving or incorrect fibre feed,

- $\quad$ presence of gas bubbles, inclusions or un-fused gaps in the splice.

For splice between single mode fibres, insertion loss $\Gamma$ resulting from core offset, MFD difference and angular misalignment is given by the following formula (Yablon, 2005), assuming a Gaussian approximation of mode fields:

$$
\Gamma=-10 \log \left[\frac{4 w_{g 1}^{2} w_{g 2}^{2}}{\left(w_{g 1}^{2}+w_{g 2}^{2}\right)^{2}} \exp \left(-\frac{4 \delta^{2}+(2 \pi / \lambda)^{2} n^{2} w_{g 1}^{2} w_{g 2}^{2} \sin ^{2} \theta}{2\left(w_{g 1}^{2}+w_{g 2}^{2}\right)}\right)\right]
$$

where $\mathrm{w}_{\mathrm{g} 1}$ and $\mathrm{w}_{\mathrm{g} 2}$ are Gaussian radii of spliced fibres, $\delta$ is lateral offset between fibre cores, $\theta$ is the angular misalignment, $\mathrm{n}$ is refractive index of fibre material and $\lambda$ the operating wavelength. Characteristics of loss due to each factor are shown in Figures 5, 6 and 7. Loss values calculated this way are only approximate because:

- mode fields in real fibres like PCF often deviate from Gaussian distribution,

- surface tension of glass produces rounded and distorted interface between fibres aligned with lateral offset (Figure 2),

- excitation of higher order modes at splice is not included.

The mode field diameter (MFD) of fibre included in technical specifications, usually measured in accordance with Petermann II definition is roughly twice its Gaussian mode radius, but definitions of both parameters are not directly comparable.

For fibres with smaller MFD, splice loss rises faster with lateral offset, but slower with angular misalignment; the resultant loss is approximately proportional to square of given misalignment. While lateral offset between fibre claddings is easy to detect visually through splicer microscope, even large angular misalignment, most often due to debris in V-grooves holding fibres may be overlooked when field of view is small or the optical system produces image distortion. This is critical in splicing large-MFD fibres for high power applications.

Accuracy of fibre alignment depends on core size and accepted loss. For splicing singlemode fibres $\left(\mathrm{w}_{\mathrm{g}}=2.5-5 \mu \mathrm{m}\right)$ with loss below $0.2 \mathrm{~dB}$, lateral core offset must be reduced to 0.5-1 $\mu \mathrm{m}$ (Figure 6). If the alignment requires cladding offset, increase of it is needed to compensate for self-centring of fibres during fusion. Splice loss can be estimated from MFD mismatch, core misalignments and deformations measured by automated analysis of splice image. True value is obtained from bi-directional measurements with optical time domain reflectometer (OTDR), as differences between backscattering intensity in fibres can produce 
relative shift of fibre traces and error in OTDR measurement of splice loss in one direction, often exceeding $1 \mathrm{~dB}$.

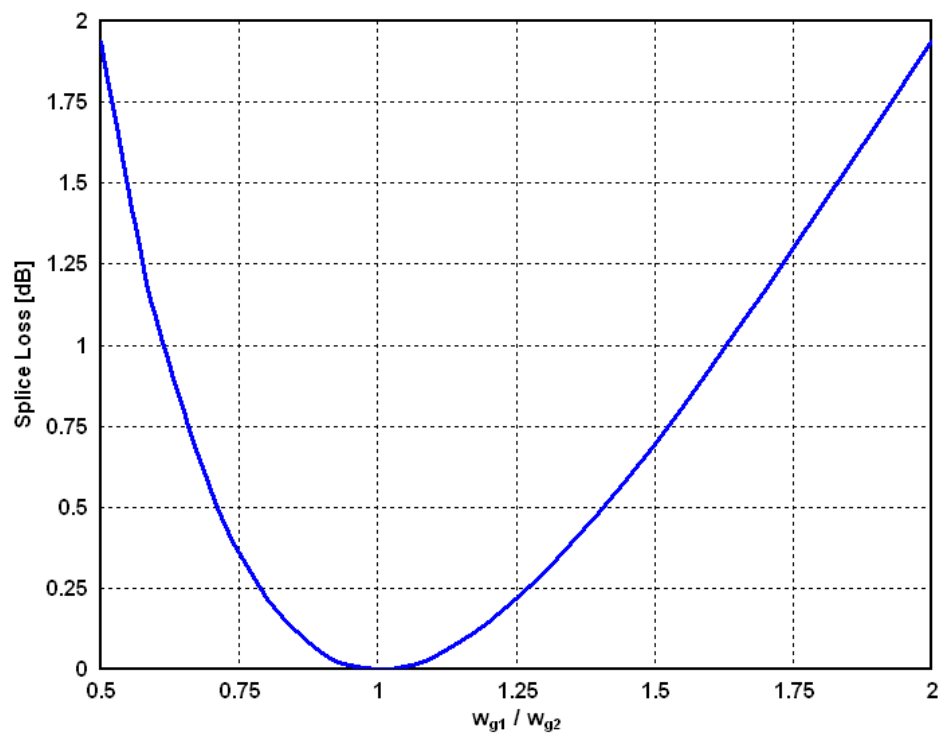

Fig. 5. Calculated loss caused by mismatch in mode field diameters of single mode fibres.

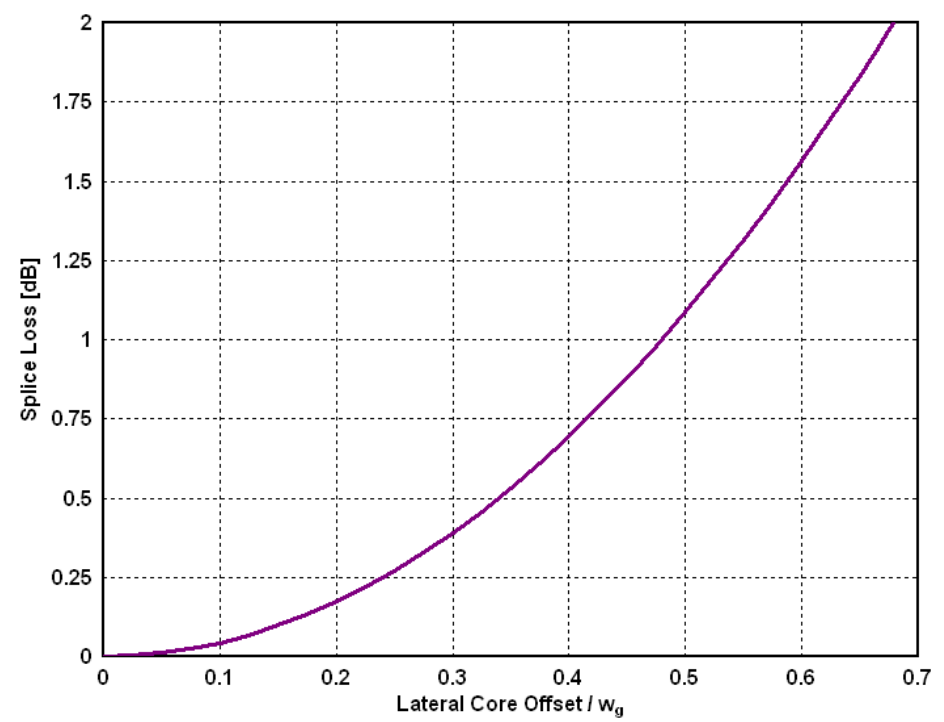

Fig. 6. Calculated loss caused by lateral offset between cores of identical single mode fibres. 
As all single-mode and multimode telecom fibres exhibit radial symmetry of core and cladding, rotational alignment of fibres is not required.

Properly made splice of identical fibres has insertion loss of around $0.05 \mathrm{~dB}$ and return loss in excess of $70 \mathrm{~dB}$. Butt-coupling with 10-15 $\mu \mathrm{m}$ gap, e.g. before fusion (Fig. 1) introduces insertion loss of approx. $0.40 \mathrm{~dB}$ and $15 \mathrm{~dB}$ return loss due to Fresnel reflection from a pair of glass/air interfaces. If a transmission loss is monitored during splicing, this difference helps to estimate splice quality. Because loss measured with laser source varies periodically with gap width due to interferometric effects (Yablon, 2005), incoherent source like LED is best. Hot fibre is a strong source of broadband thermal radiation, with emission peak close to $780 \mathrm{~nm}$ at $2000^{\circ} \mathrm{C}$, preventing loss measurements during discharge.

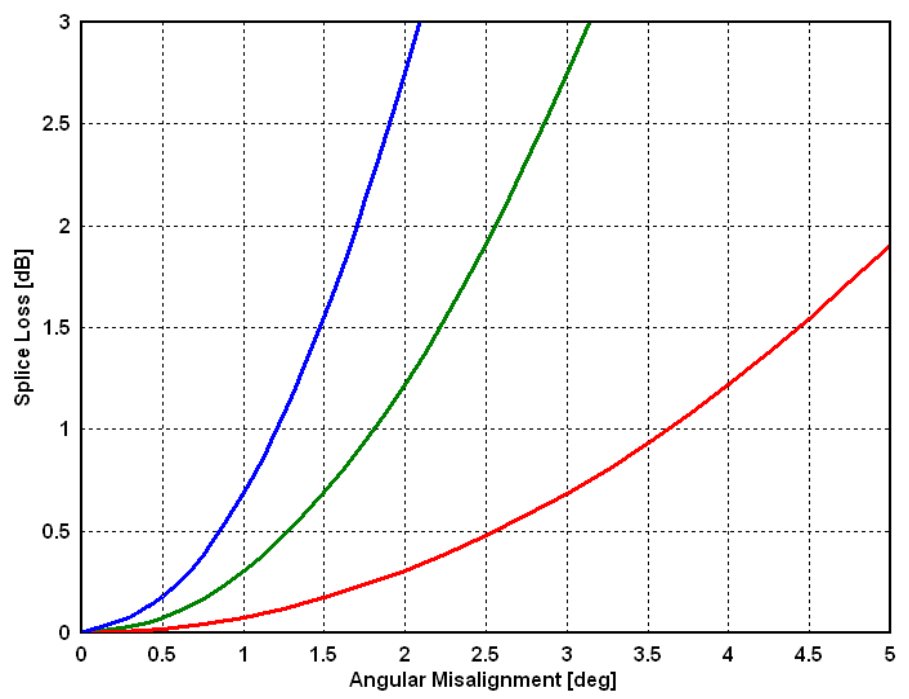

Fig. 7. Calculated loss caused by angular misalignment of identical single mode fibres. $\lambda=1.55 \mu \mathrm{m}, \mathrm{n}=1.5$. Blue: $\mathrm{w}_{\mathrm{g}}=7.5 \mu \mathrm{m}$, green: $\mathrm{w}_{\mathrm{g}}=5 \mu \mathrm{m}$, red: $\mathrm{w}_{\mathrm{g}}=2.5 \mu \mathrm{m}$.

Loss of splice between single-mode fibres usually shows weak wavelength dependence, because MFD increases with wavelength, typically by $10-20 \%$ between 1310 and $1550 \mathrm{~nm}$ (Corning, 2008). If the main source of loss is core offset, it falls with wavelength, while angular misalignment produce loss rising with wavelength, in both cases in proportion to square of MFD. For multimode fibres, splice loss is essentially wavelength-independent.

Strong increase of splice loss with wavelength shown in Figure 8 indicates excessive fibre bending due to improper handling, tight coiling or squeeze in the vicinity of splice.

For example, while single splice between fibres having 1:2 MFD ratio has best-case loss of $1.94 \mathrm{~dB}$, two splices with $1: 1.41: 2$ MFD ratio have combined loss $2 \times 0.51=1.02 \mathrm{~dB}$. This approach was adopted for splicing a small-core DCF with MFD of 2-4 $\mu \mathrm{m}$ to typical SMF having 8-11 $\mu \mathrm{m}$ MFD (Edvold \& Gruner-Nielsen, 1996), and later to splice dissimilar PCFs (Xiao et al., 2007). Extra intermediate fibres can reduce loss further, e.g. to $0.56 \mathrm{~dB}$ for 4 splices and 1:2 MFD ratio, but difficulty with finding necessary fibres, losses due to other factors and additional labour usually make such efforts impractical. 


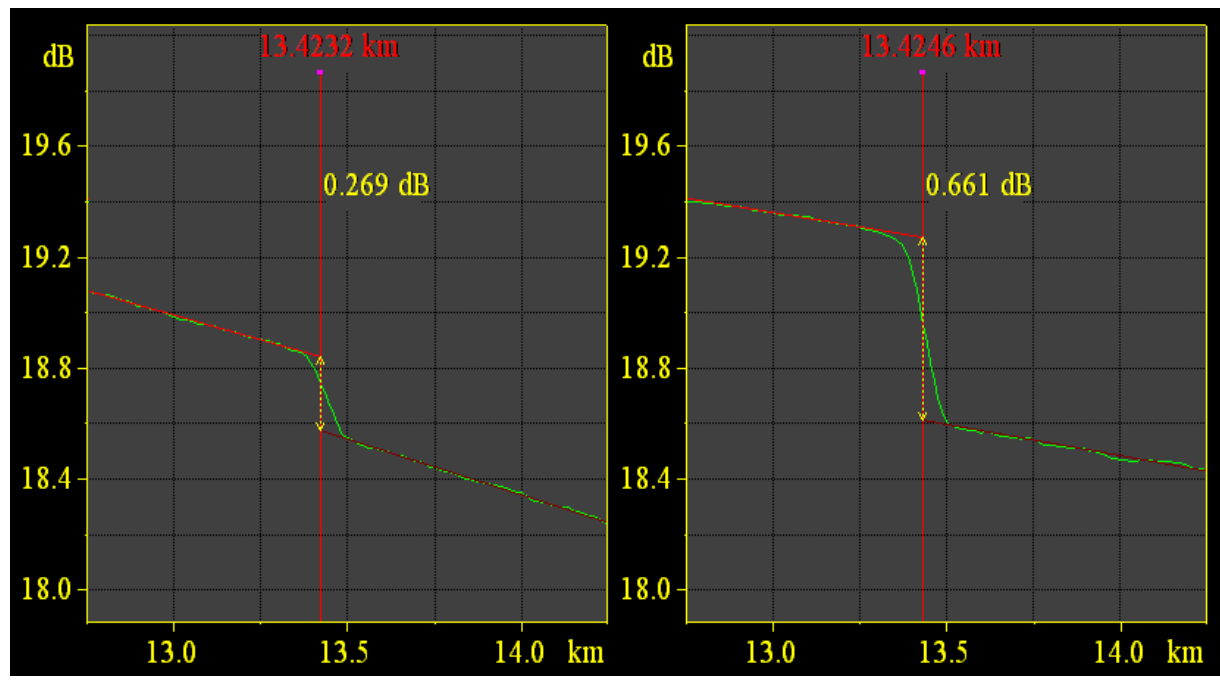

Fig. 8. Sharp bend of SMF observed with OTDR at $1310 \mathrm{~nm}$ (left) and $1550 \mathrm{~nm}$ (right).

If fibres having substantially different MFD must be spliced, loss can be reduced by introduction of short fibre with intermediate MFD, as shown in Figure 9.

(a) Direct splicing

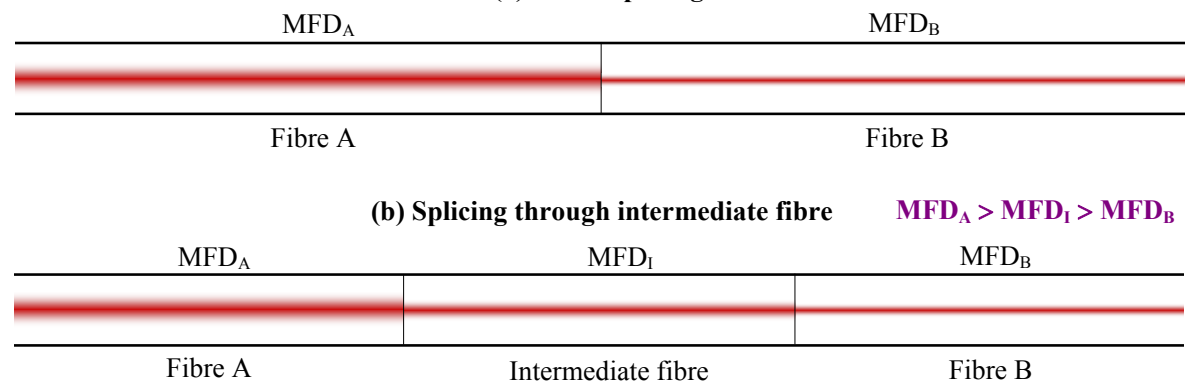

Fig. 9. Principle of splicing through intermediate fibre.

\subsection{Splicing of plastic optical fibres}

Fusion splicing of plastic optical fibres (POF) made of poly-methyl-methacrylate (PMMA) or TOPAS polymer is very hard. For example, the tip of microstructured fibre made of PMMA forms a cone when heated, instead of rounding typical for fused silica fibre (Figure 10).

Filament splicing and split-mould fusion of POF were reported, but failed to find acceptance. Butt-coupling is adopted for large diameter (up to $1 \mathrm{~mm}$ ) solid POFs used in car, aircraft and industrial networks, and gluing is used as well. Microstructured plastic optical fibre (mPOF) can be glued, also to glass fibre (Bang, 2010). Polymer fibres are cleaved by cutting with razor blade at controlled speed. Blade and fibre must be heated; the temperature range for PMMA fibres is $60-90^{\circ} \mathrm{C}$ (Law et al., 2006). 


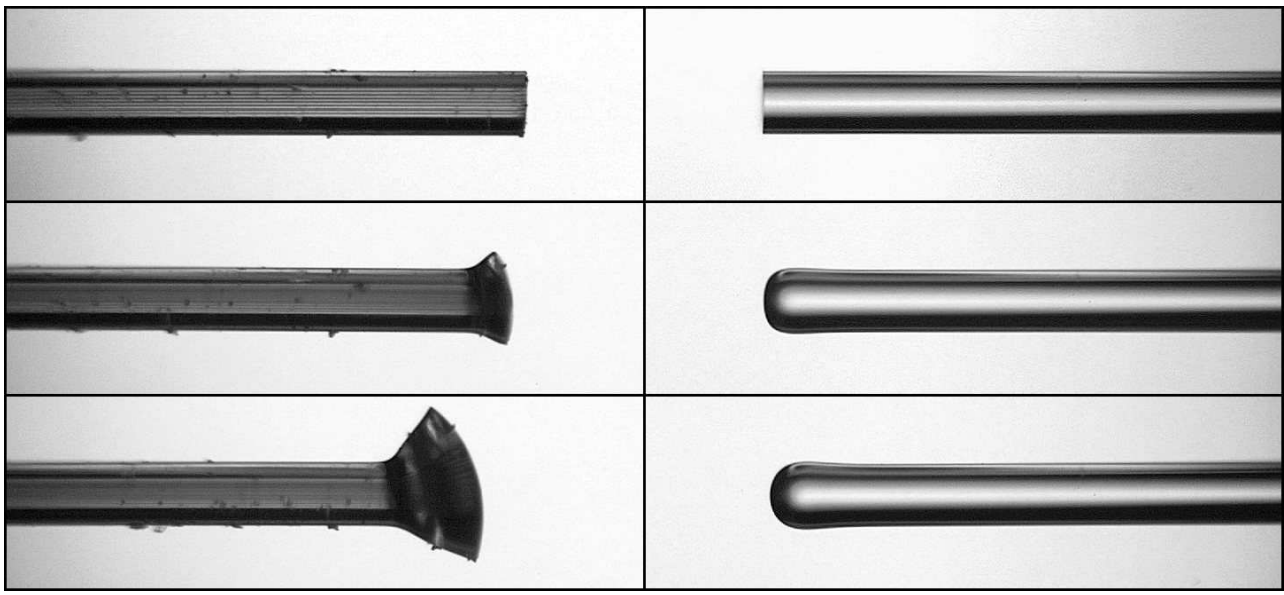

Fig. 10. Deformation of fibre tips by heat of electric arc: DTU MIK125/0.5 made of PMMA (left) and Corning SMF-28 made of fused silica (right). Top: cleaved fibres, middle: after 1st heating, bottom: after 2 nd heating.

Handling and splicing of thin $\mathrm{mPOF}$ with standard equipment is difficult due to softness of polymers in comparison to fused silica. In experiments at NIT, mPOF of $125 \mu \mathrm{m}$ diameter exhibited unacceptable sag and curl when clamped $4 \mathrm{~mm}$ away from tip, while standard V-groove clamps usually damaged the fibre.

\section{Fusion splicing of PCFs}

This section presents some issues specific to fusion splicing of silica "holey" fibres, primarily of single mode PCF to SMF. Due to large variety of designs, actual procedure, power, time and geometry settings must be individually tailored.

Finished splice must be protected to have adequate mechanical strength, as holes and flaws on their surfaces make PCFs inherently weaker than solid fibres. In all experiments at NIT, fusion splices were protected with commercial $60 \mathrm{~mm}$ heat shrinkable sleeves reinforced with stainless steel rod. Protected splices performed well during temperature cycling between $-40^{\circ} \mathrm{C}$ and $+80^{\circ} \mathrm{C}$, with loss stability better than $\pm 0.05 \mathrm{~dB}$, and as grips for application of twist and tensile forces in mechanical tests (Figure 11).

Fusion splices are hermetic, keeping external contaminants out, but trapping whatever entered earlier. Exceptions include helium and hydrogen, diffusing through $60 \mu \mathrm{m}$ thick fused silica cladding in few hours. Short suspended core PCF infiltrated with acetylene $\left(\mathrm{C}_{2} \mathrm{H}_{2}\right)$ or hydrogen cyanide $(\mathrm{HCN})$ and fusion spliced to SMF pigtails is used as optical frequency reference, e.g. for calibration of optical spectrum analyzers (Thapa et al., 2006).

Out-gassing of cleaved PCF is fast, but removal of liquid or dust is essentially impossible due to high pneumatic resistance of thin holes and adsorption to the surface of their walls.

Infiltration of holes with gas or liquid allows to make fibre sensors for chemical analysis, detection of pollutants or poison gas, medical diagnostics, etc. through spectral absorption 
measurements. Filling with liquids, including liquid crystals or suspensions of solid particles in oils allows to build tuneable, nonlinear or electrically controlled optical devices.

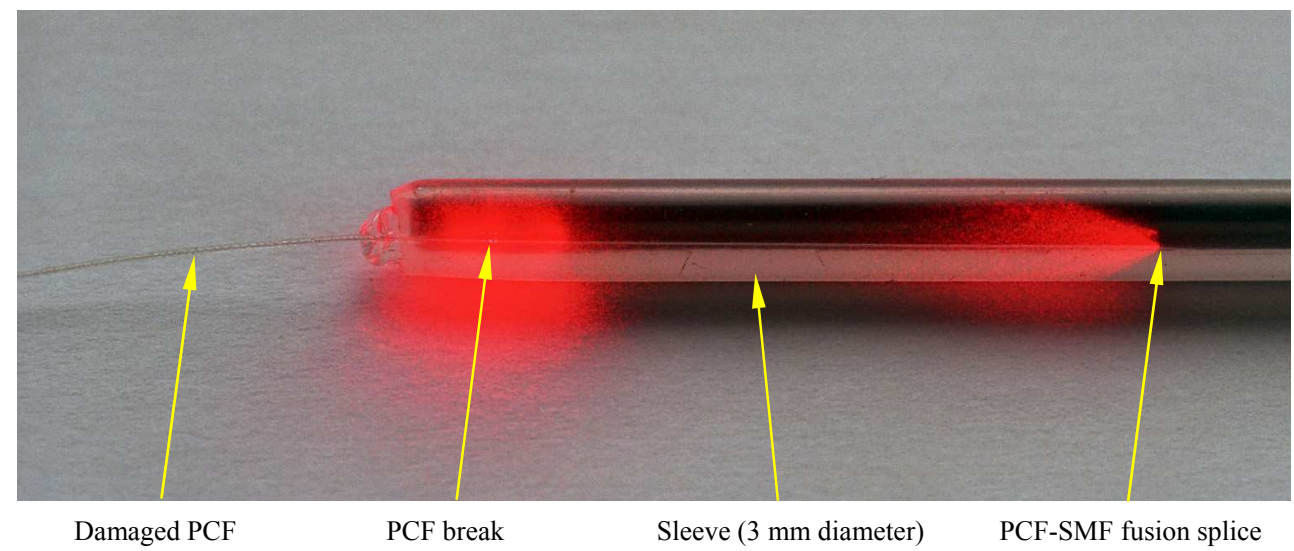

Fig. 11. $80 \mu \mathrm{m}$ PCF (IPHT 252b5) in acrylate coating broken by $180 \mathrm{rev} / \mathrm{m}$ twist applied using heat shrinkable sleeve as grip. $4 \mathrm{~mm}$ section of fibre inside sleeve was long enough to transfer a destructive force. Splice was illuminated with $650 \mathrm{~nm}$ laser through SMF (right).

PCFs are sometimes fused for purposes other than splicing, like:

- sealing of fibre before storage or shipment,

- consolidation of fibre tip prior to polishing.

Fusion power and duration must ensure robust collapse of all holes.

\subsection{Issues and solutions specific to fusion splicing of PCFs}

Besides issues presented in section 3, work with PCF brings several new challenges:

1. Solvents used for fibre cleaning infiltrate PCF holes.

2. Holes distort propagation of crack and hamper fibre cleaving.

3. Surface tension of molten silica causes collapse of holes.

4. PCF has lower fusion temperature and thermal conductivity than solid fibre.

5. Mismatch in fiber cladding diameters results in sharp edges, splice strength suffers.

6. Mode fields of PCFs do not exhibit full radial symmetry.

7. Photonic structure supports undesirable propagation of light outside of fibre core.

8. High attenuation and strong backscattering in PCF affect splice loss measurements.

It is often needed to splice PCFs having unusual cladding diameter, core design and MFD, as there are no standards for this category of fibres. Most commercially available splicing and test equipment, tools and accessories like fibre adaptors or protective sleeves are designed strictly for telecom fibres with $125 \mu \mathrm{m}$ cladding and 250-900 $\mu \mathrm{m}$ coating.

A compromise between achieving different goals is often required, particularly between splice loss and its mechanical strength. Also, unless optimization of manufacturing process, device performance, etc. justifies labour and equipment costs involved, time and funds available for trials are limited and less-than-perfect solutions need to be accepted. 


\subsubsection{Fibre infiltration}

Unless PCF end is sealed by fusion, low-viscosity liquid applied to it penetrates holes. Filling with colourless acetone, isopropyl alcohol, ethyl alcohol or water is invisible through coating. Removal is practically impossible, with the following consequences:

- Fall of index contrast in the infiltrated zone when solvent (isopropyl alcohol: $\mathrm{n}=1.38$, acetone, ethyl alcohol: $\mathrm{n}=1.36$, water: $\mathrm{n}=1.33,589 \mathrm{~nm}$ wavelength) replaces air $(n=1.00)$ in contact with fused silica $(n=1.46)$. Light guiding is disturbed, and loss changes with movement of solvent, interfering with alignment of fibres.

- During fusion, solvent in hot zone partly decomposes leaving thin layer of dark carbon residue on hole walls and partly evaporates, with pressure pushing the remaining liquid deeper into PCF. Resulting loss observed at NIT was up to $50 \mathrm{~dB}$.

For the same reason, PCFs cannot be connectorized in conventional way because water and small $(0.5-3 \mu \mathrm{m})$ particles of polishing materials enter holes. To avoid infiltration, fibre ends shall be protected against liquids, dust or vapours during handling and storage. In particular, water vapour degrades fibre strength by producing flaws on walls of holes. PCF is best stripped mechanically and dry wiped to remove remains of coating. When use of solvent, acid, etc. is required, fibre end must be first sealed by fusion. PCF contamination in storage or shipping can be prevented by fusing both ends. To fit a connector, PCF can be stripped, cleaved and fused to collapse holes over a 100-200 $\mu \mathrm{m}$ length and fixed in the connector ferrule for polishing. This procedure works best for fibres with doped core, whose light guiding properties are retained without photonic structure.

\subsubsection{Fibre cleaving}

Cleaving of glass fibres uses perpendicular propagation of indentation-initiated break at the speed of sound, approx. $5950 \mathrm{~m} / \mathrm{s}$ for fused silica. Structures made of differing materials, like arrays of holes in PCF or inserts of $\mathrm{B}_{2} \mathrm{O}_{3}-\mathrm{SiO}_{2}$ glass in PANDA fibre distort this propagation; these fibres are reportedly more difficult to cleave than conventional ones.

PCFs tested at NIT, with 80-200 $\mu \mathrm{m}$ cladding diameter were cleaved using a typical, simple cleaver for telecom fibres with tungsten carbide blade. Proportion of bad cleaves was around $20 \%$, a little higher than experienced with most SMFs. It rose to some $50 \%$ for the $80 \mu \mathrm{m}$ IPHT 252b5, presumably because tensile load was excessive for this fibre with equivalent diameter of solid glass of just $72 \mu \mathrm{m}$. This is consistent with literature data that best tensile load is proportional to cladding diameter raised to power of 2/3 (Yablon, 2005).

Cleaved PCFs shall be carefully inspected for perpendicular cut before further work. For non-standard fibre sizes, use of cleaver with adjustable tensile force is recommended.

\subsubsection{Collapse of holes and thermal issues}

In absence of differential pressure, surface tension in molten glass causes the holes to reduce their radius at constant linear speed set by the following formula (Yablon, 2005):

$$
v_{\text {collapse }}=\frac{\gamma}{\eta}
$$


where $\gamma$ is surface tension, almost constant, and $\eta$ is glass viscosity falling with temperature (Figure 3). If this continues long enough, holes collapse and solid fibre of reduced diameter is created. Collapse of holes can be prevented by internal gas pressure ("inflation"); equilibrium pressure $P_{\text {critical }}$ for capillary is a function of its inner $\left(r_{i}\right)$ and outer $\left(r_{o}\right)$ radius:

$$
P_{\text {critical }}=\gamma\left(\frac{1}{r_{i}}+\frac{1}{r_{o}}\right)
$$

In PCF with holes of differing sizes, the largest holes disappear last and over the shortest length. Due to longitudinal temperature gradient, only some length of PCF is subjected to collapse of holes, with gradual "thinning" in the intermediate zone - see Figures 12 and 13.

For internal fibre temperature independent of depth, all holes of given size shall collapse simultaneously, but in experiments (Xiao et al., 2007, Bourliaguet et al., 2003) holes located deeper are less affected. Example from our work is shown in Figure 13. Transfer of heat from fibre surface to its interior, predominantly of radiative type, is apparently delayed.

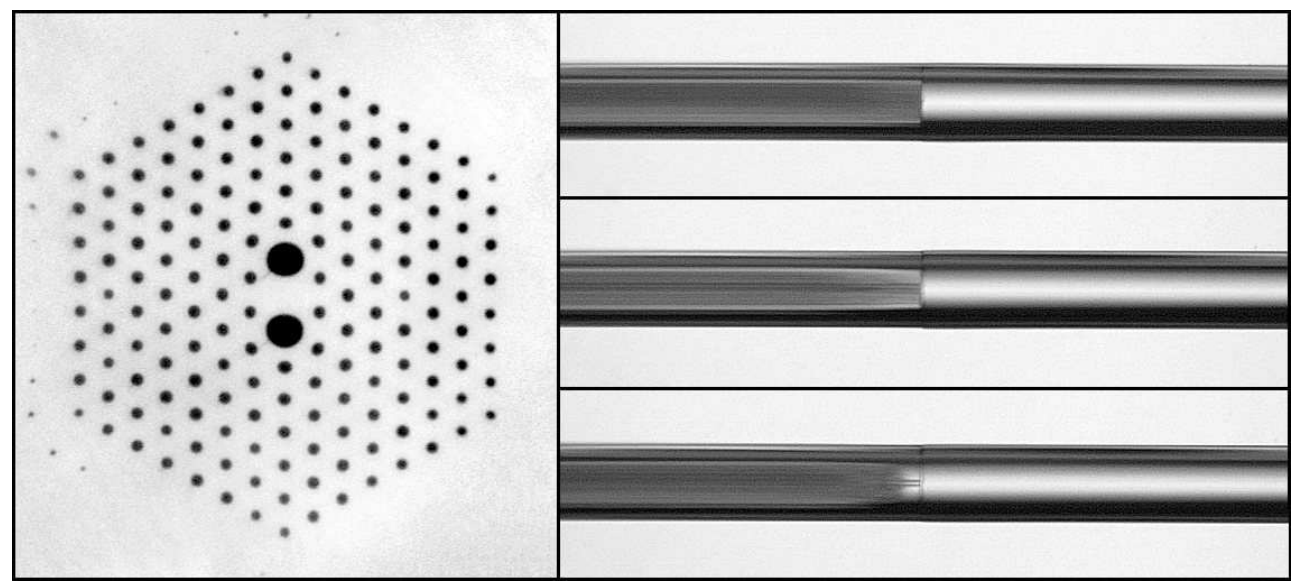

Fig. 12. Structure of PCF (UMCS 070119p2) with $3.5 \mu \mathrm{m}$ and $1.3 \mu \mathrm{m}$ holes and views of fusion splice to SMF. Fusion time: $0.3 \mathrm{~s}$, fusion current from $13 \mathrm{~mA}$ (top) to $15 \mathrm{~mA}$ (bottom).

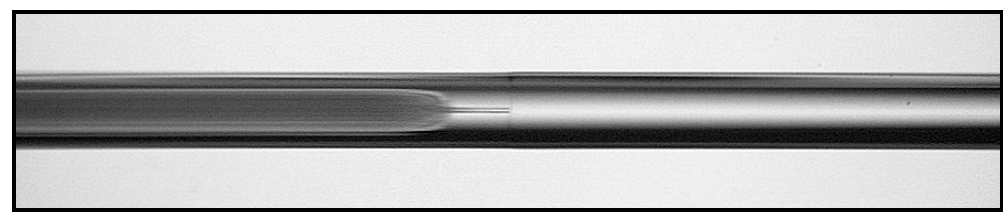

Fig. 13. Depth-dependent and diameter-dependent collapse of holes (UMCS 070119p2).

In the solidified length of fibre, light beam expands freely and proportion of power coupled to core of other fibre drops with increase of collapsed zone. Collapse of holes shall be avoided as much as possible, and if it cannot be avoided, fibre length affected must be reduced to absolute minimum. PCFs with doped core are partial exception. 
Collapse is minimized by shortening fusion time to $0.2-0.5 \mathrm{~s}$ from $1-2 \mathrm{~s}$ for solid $125 \mu \mathrm{m}$ fibres and reducing power, fusion time being more important. However, too short fusion time and too low temperature prevent full fusion of fibre-fibre boundary and proper rounding of edges if fiber diameters don't match, as the glass is too viscous and/or doesn't have enough time to flow. There is a trade-off between achieving low splice loss with little heat or good strength with more, and splice with excellent optical transmission may not be strong enough even for removal from splicing machine, as shown in Figure 14.

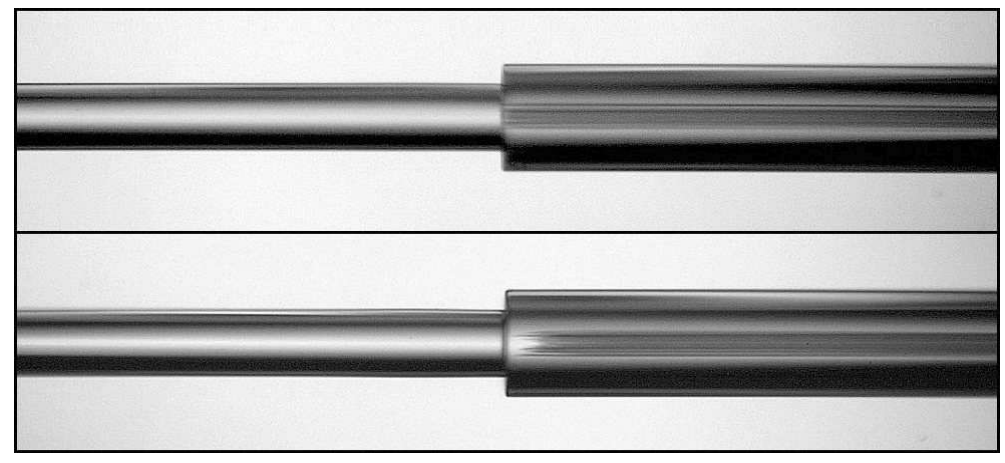

Fig. 14. Splices between $204 \mu \mathrm{m}$ PCF (IPHT 212b1) and SMF, fused with $150 \mu \mathrm{m}$ axial offset. Splice with intact photonic structure and lowest loss, which broke during handling (top), and splice that survived (bottom). Fusion current: 18-19 mA, fusion time: $0.5 \mathrm{~s}$.

In splicing dissimilar fibres, axial offset of fibre contact point from the axis of electrodes is useful. The more heat-sensitive fibre - PCF in splice to SMF, or smaller of two PCFs, is kept away from centre of discharge column and its temperature is lower. In experiments at NIT, maximum axial offset was 1.2-1.5x fibre cladding diameter, otherwise unacceptable fibre deformation occurred in the hottest zone. Reduced fibre overlap can help.

\subsubsection{Mismatch in cladding diameter}

The power required to achieve given fibre temperature is approximately proportional to cladding diameter, and when fibres of different diameters are fused, the thinner fibre must receive a smaller share of arc power to obtain symmetrical temperature distribution. This is ensured by axial offset of arc centre in direction of thicker fibre. When splicing PCF to solid fibre, PCF shall be colder to prevent collapse of holes, adding second component of axial offset. In effect, even when PCF is moderately thicker than solid fibre, there is usually no offset towards PCF.

During fusion of fibres of different diameters, poor smoothing of corners at fibre-fibre transition and fragility of splice are common, as seen in Figure 14. Therefore, fusion power and duration are often selected to obtain the minimum splice strength allowing handling without break, even if collapse of holes and increased splice loss are to be accepted.

\subsubsection{Non-circular mode}

Typical photonic structure, e.g. of "honeycomb" type, lacks full radial symmetry and mode field distribution reflects shape of it. In PCF with circular doped core, mode field can be still 
more or less distorted, depending on interactions with surrounding holes. Many PCFs for signal processing, sensing, optical switching etc. have cores and/or photonic structure made deliberately non-symmetrical; mode field distribution is non-circular, but usually with lateral symmetry, and propagation is polarization-dependent.

Additionally, current PCF manufacturing technology cannot ensure perfect fibre geometry. Holes are often distorted during fibre drawing (Figure 15), affecting mode field shape.

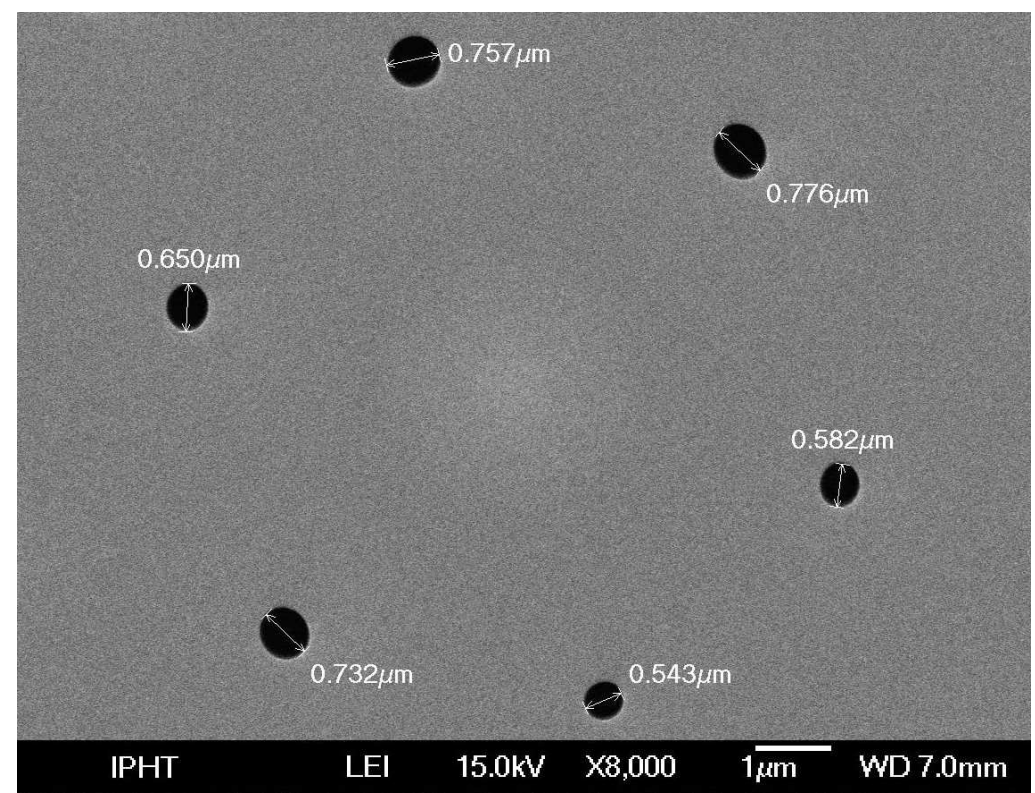

Fig. 15. Central part of doped-core PCF (IPHT 282b4) with deformed holes.

If the PCF is spliced to radially symmetrical fibre, like single-mode or multimode telecom fibre, relative rotation has no effect on splice parameters, and simpler fusion splicing machine without fibre rotation is sufficient. Rotational alignment is necessary for splicing PCF to another PCF or specialty fibre of non-circular design like Bow-Tie or PANDA. Alignment is based either on observation of fibre structure through microscope of splicing machine or monitoring of transmission through butt-coupled fibres. In the latter case, a source of linearly polarized light properly coupled to one fibre is often required.

\subsubsection{MFD mismatch}

This problem is not limited to PCFs - see section 3.4. Besides use of intermediate fibre(s), one can locally change MFD of one fibre to make it more compatible with another or modify propagation in the zone between fibres. Several methods were reported, including:

- Heat-assisted diffusion of dopants to expand small core doped with $\mathrm{GeO}_{2}$, by heating on the splicing machine. Fluorine-doped fibre can be modified as well (Yablon, 2005, Edvold \& Gruner-Nielsen, 1996). Transition zone shall be at least $300 \mu \mathrm{m}$ long. 
- $\quad$ Slow pulling of hot $\left(1200-1500^{\circ} \mathrm{C}\right)$ fiber to reduce its diameter and MFD before cleaving in the middle of thinned section (fiber tapering). Fusion splicing machine is used, with arc power somewhat lower than required for pre-fusion.

- Melting of fibre tip to make a ball lens. Arc power is similar to used for fusion (Wang et al., 2008, Borzycki et al., 2010a). Fibres with lenses are than fused - see 4.2.2.

- Collapsing a controlled length of small-core PCF. This results in Gaussian expansion of light beam towards interface to fibre with larger core.

- Insertion of GRIN fibre lens between two spliced fibres (Yablon \& Bise, 2004). GRIN type and length must be carefully chosen to ensure proper focusing of light.

While effective, these techniques are sensitive to deviations in process parameters. Specific advice for different cases can be found in literature, but several techniques require splicing machine with precise control of fibre movements, in particular for fibre tapering.

\subsubsection{Propagation of light in photonic structure and splice loss measurements}

In single-mode propagation regime, insertion loss of splice is independent of transmission direction. Non-reciprocity indicates multimode propagation in one or both fibres.

Excitation of higher order modes, e.g. at splice with lateral offset is known in telecom systems, but mostly limited to short fibres, as higher order modes are strongly attenuated. In PCFs, photonic structure can support persistent propagation of own modes, especially as short lengths of such fibres, $\leq 1 \mathrm{~m}$ are common. This produces interference in measurements, sensing or operation of optical devices, as detectors in active instruments respond to total optical power of all modes. Examples of related measurement problems are:

- non-reciprocity of splice loss between SMF and PCF,

- noise-like interference in measurements of differential group delay (DGD) and polarization dependent loss (PDL) of PCF samples, see Fig. 17 (Borzycki et al., 2011a).

Non-reciprocity of splice loss measured with optical source and optical power meter is due to different propagation of higher-order modes. In SMF, this part of radiation escapes fibre core and is lost, leaving only the fundamental mode. In PCF, part of it reaches the end of fibre and detector of power meter (Figure 16); loss indicated by instrument connected to PCF is lower than "true" value for fundamental mode. OTDR test is less affected, as optical pulse travels through splice in both directions and the instrument shows average loss value.

(a) Propagation from PCF to SMF

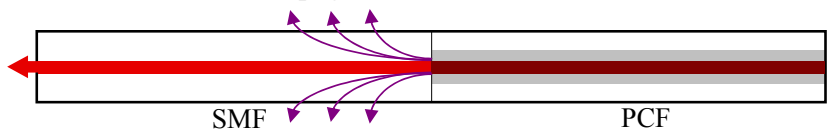

(b) Propagation from SMF to PCF

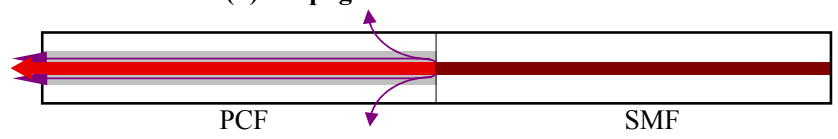

Fig. 16. Mechanism creating non-reciprocal loss in PCF-SMF splices. 

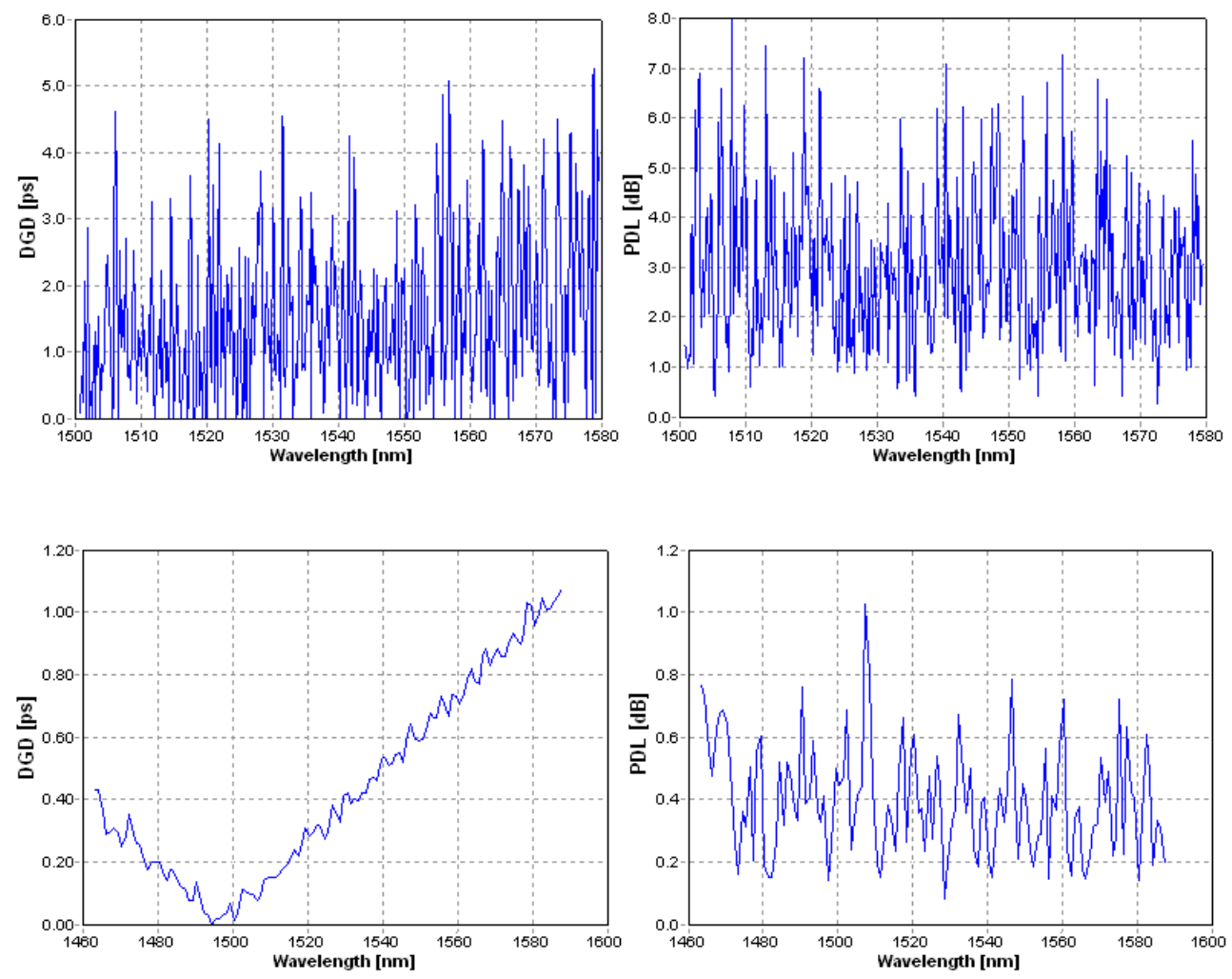

Fig. 17. DGD and PDL of $20.2 \mathrm{~m}$ and $18.7 \mathrm{~m}$ long samples of PCF prone to multimode propagation (IPHT 252b3) with poor (top) and optimized (bottom) fusion splices to SMFs.

Loss measurements are needed to align fibres, monitor fusion, and evaluate finished splice. It is often necessary to measure total loss of circuit or device incorporating PCF rather than splice(s) alone. There are two basic test methods:

- Transmitted power monitoring with optical source and optical power meter,

- $\quad$ OTDR, with lengths of fibres adjacent to splice required.

The first technique allows fast measurements (0.1-1 s) with high resolution (0.001 dB). As typical laser source emits linearly polarized light, apparent PCF-SMF splice loss during alignment varies with fiber rotation due to PCF non-circular structure. In experiments presented in section 4, loss was monitored during fibre alignment and after each fusion step. Test setup shown in Figure 18 was used, including HP8153A optical multimeter with HP81553SM laser source $(1558 \mathrm{~nm})$ and HP81532A power meter modules. For splice No. 1 it was necessary to subtract PCF loss, measured separately with OTDR and connector loss; loss of splice No. 2 was measured directly. Loss calculations must take into account high attenuation of PCF, usually $20-200 \mathrm{~dB} / \mathrm{km}$. Data in section 4.2 refer to splice No. 2. 


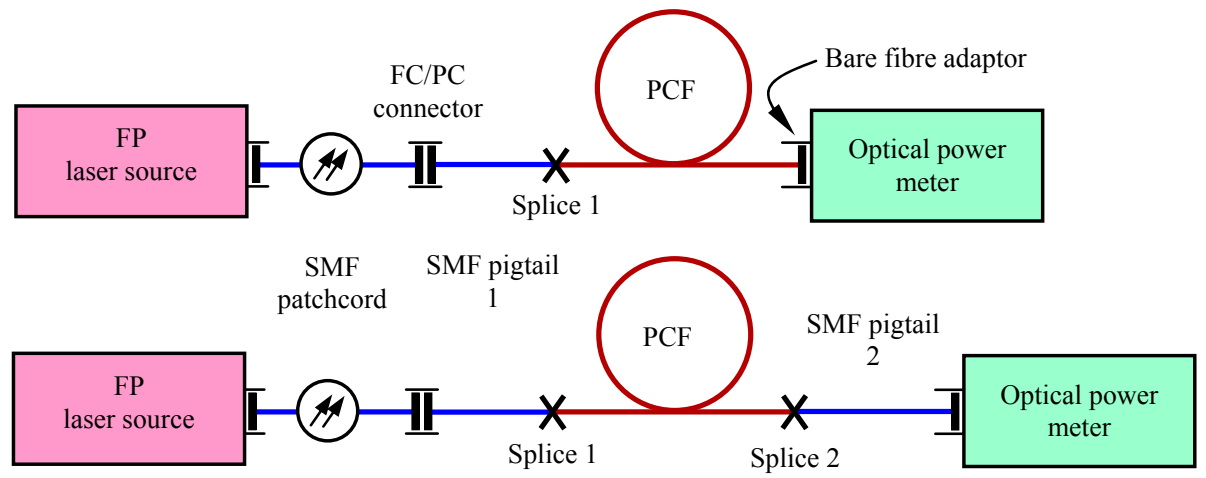

Fig. 18. Setups for loss measurements. Measurement of splice No. 1 after separate PCF attenuation measurement (top), direct measurement of splice No. 2 (bottom).

When bare fiber adapters are used, debris on PCF endface can produce errors. PCF tip could be cleaned by gentle contact with suitable sticky tape, like Scotch Magic (Figure 19).

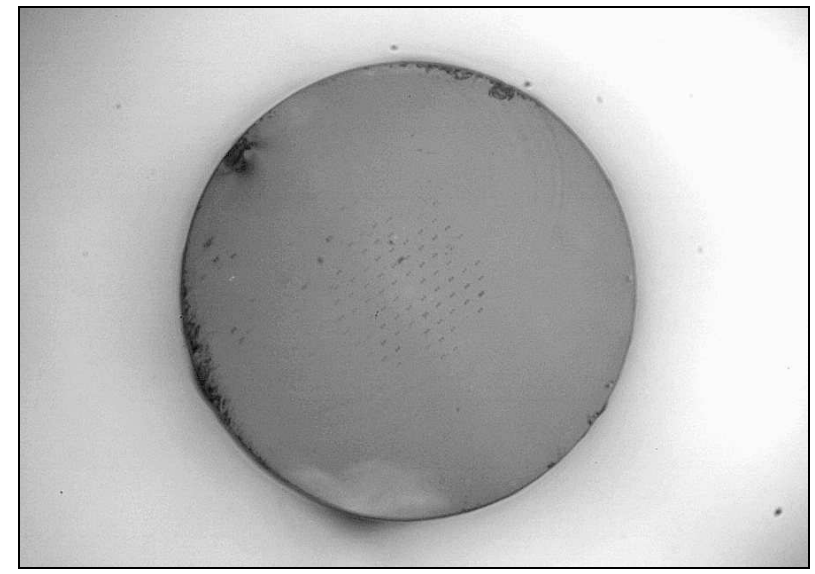

Fig. 19. Cleaved IPHT 282b4 in bare fibre adapter after cleaning of dust with sticky tape.

OTDR measurement of SMF-PCF splice(s) and PCF itself requires certain length of fibre before and after the splice, at least $50 \mathrm{~m}$ for instrument with $10 \mathrm{~ns}$ pulse width (Figure 20).

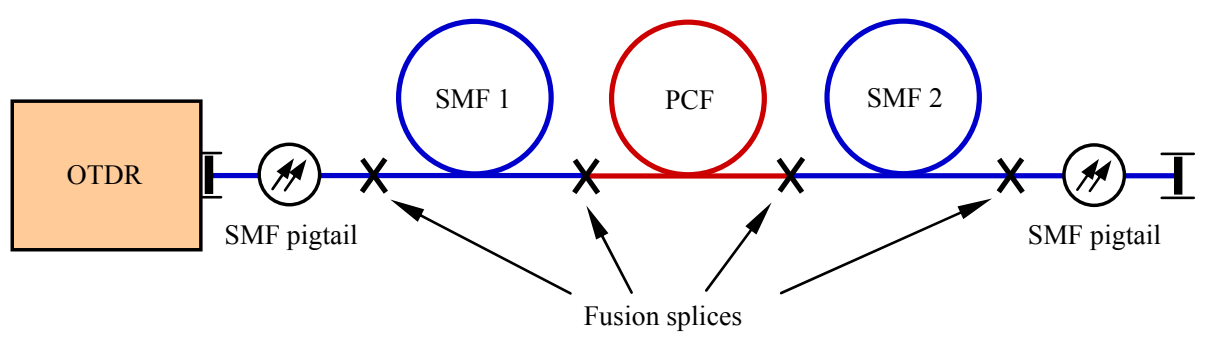

Fig. 20. Arrangement for characterization of PCF and PCF-SMF splices with OTDR. 
Large differences of backscattering intensity in PCF and SMF are common, and true loss $\Gamma$ of SMF-PCF splice can be established only with bi-directional measurement and averaging:

$$
\Gamma=\frac{\Gamma_{A}+\Gamma_{B}}{2}
$$

where $\Gamma_{\mathrm{A}}$ and $\Gamma_{\mathrm{B}}$ are apparent splice losses measured in $\mathrm{A}$ and $\mathrm{B}$ directions.

Many PCFs produce strong backscattering due to entrapment of scattered light by photonic structure and intense scattering in doped core, if present (Borzycki et al., 2010b, 2011a). This brings noise-free OTDR trace, but one-way OTDR measurement are misleading (Figures 21 and 22). In Figure 22, trace of highly $\mathrm{GeO}_{2}$-doped PCF (IPHT 282b4) was shifted by $9.5 \mathrm{~dB}$ vs. traces of SMFs, producing "gain" in splice before PCF and exaggerated loss of splice after PCF (Borzycki et al, 2011b). Testing such samples requires high-performance OTDR.

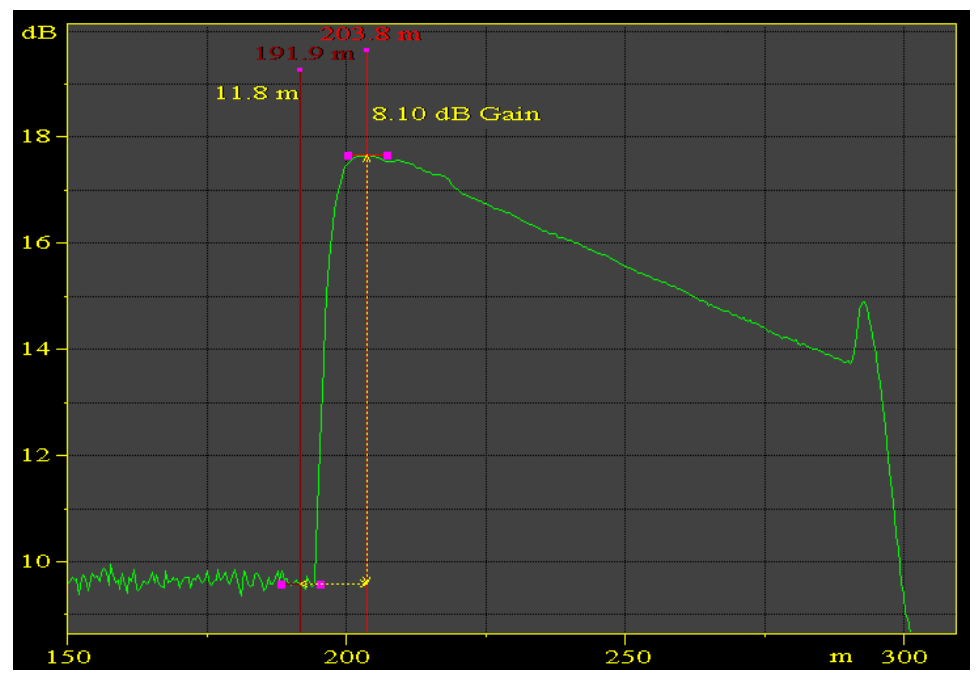

Fig. 21. OTDR trace of SMF, PCF-SMF splice and PCF (IPHT 282b3) acquired with setup shown in Figure 20. Wavelength: 1550 nm, pulse width: $10 \mathrm{~ns}$, PCF length: $91 \mathrm{~m}$. Instead of $8.1 \mathrm{~dB}$ "gain", the splice had actual loss of $2.2 \mathrm{~dB}$.

In PCF characterization, improvements to quality of splices pay off with improved accuracy and fewer measurement artifacts, especially in measurements of polarization properties.

\subsection{Examples}

Descriptions below apply to splicing of SMF to PCFs designed and made at IPHT Jena, Germany as highly nonlinear single-mode fibres for signal processing, like wavelength conversion. For this, fibre cores were strongly doped with $\mathrm{GeO}_{2}$, up to $36 \%$ mol. The reader is referred to separate papers on manufacturing of these fibres (Schuster et al, 2007) and their characterization (Borzycki et al., 2010b). Data of all PCFs referred to in this chapter are presented in Table 2. UMCS 070119p2 mentioned in section 4.1.3 was a "PANDA-like" birefringent fibre developed at UMCS Lublin, Poland for use in polarimetric sensors. 


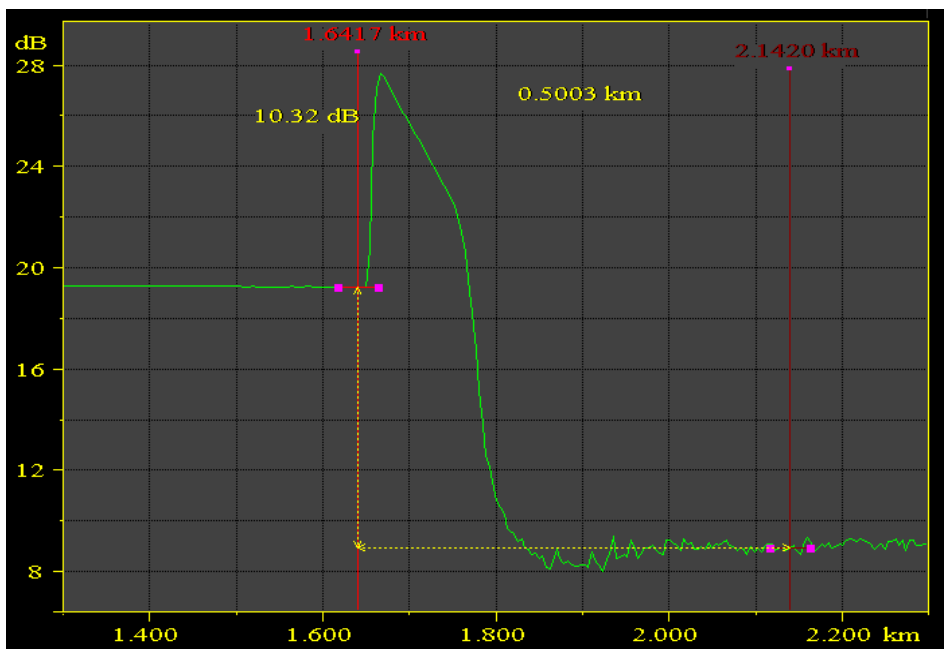

Fig. 22. OTDR trace of PCF (IPHT 282b4) spliced to SMFs as in Figure 20. Wavelength: $1550 \mathrm{~nm}$, pulse width: $100 \mathrm{~ns}$, PCF length: $104 \mathrm{~m}$.

\begin{tabular}{|l|c|c|c|c|c|c|}
\hline Parameter & Unit & $\begin{array}{c}\text { IPHT } \\
252 \mathrm{~b} 5\end{array}$ & $\begin{array}{c}\text { IPHT } \\
252 \mathrm{~b} 3\end{array}$ & $\begin{array}{c}\text { IPHT } \\
282 \mathrm{~b} 3\end{array}$ & $\begin{array}{c}\text { IPHT } \\
282 \mathrm{~b} 4\end{array}$ & $\begin{array}{c}\text { UMCS } \\
\text { 070119p2 }\end{array}$ \\
\hline Cladding diameter & $\mu \mathrm{m}$ & 82.7 & 127.5 & 125.9 & 124.4 & 126 \\
\hline Hole diameter $(\mathrm{d})$ & $\mu \mathrm{m}$ & 3.6 & 5.8 & 0.7 & 0.7 & $3.5 / 1.3$ \\
\hline Hole spacing $(\Lambda)$ & $\mu \mathrm{m}$ & 4.2 & 6.5 & 4.4 & 4.2 & 3.5 \\
\hline Diameter of holey package & $\mu \mathrm{m}$ & 42.8 & 61.5 & 44.6 & 43.0 & 55 \\
\hline Diameter of doped core & $\mu \mathrm{m}$ & $0.5 / 2.0 / 4.1^{*}$ & $1.4 / 3.3 / 6.6^{*}$ & $0.8 / 2.8 / 7.1^{*}$ & $1.2 / 3.9 / 7.3^{*}$ & $\mathrm{~N}^{*} \mathrm{~A}^{* *}$ \\
\hline
\end{tabular}

*) Central high $\mathrm{GeO}_{2}$ doped core / $\mathrm{GeO}_{2}$ doped socket / total core diameter.

*) No doped core.

Table 2. Data of photonic crystal fibres
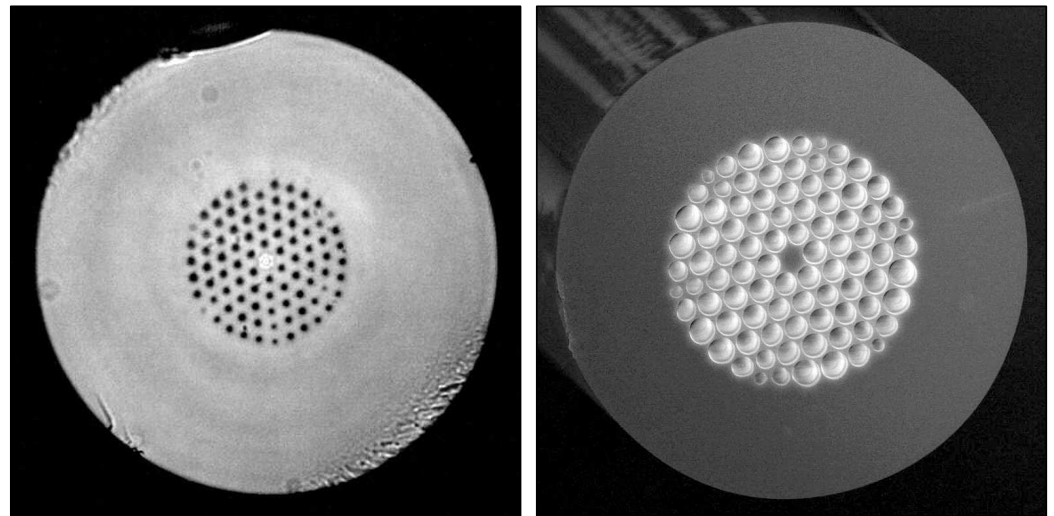

Fig. 23. Cross-sections of fibres: IPHT 282b4 (left) and IPHT 252b5 (right). 


\subsubsection{Splicing IPHT 282b4 to SMF}

Being similar to SMF, this fibre was spliced in the same way, using the following fusion program (pre-fusion, fusion, annealing - Figure 4): $9 \mathrm{~mA}-3 \mathrm{~s} / 17 \mathrm{~mA}-0.5 \mathrm{~s} / 9 \mathrm{~mA}-3 \mathrm{~s}$.

PCF length, attenuation and loss at $1558 \mathrm{~nm}$ were $12.4 \mathrm{~m}, 61.5 \mathrm{~dB} / \mathrm{km}$ and $0.76 \mathrm{~dB}$ respectively. The SMF fibre was Corning SMF-28 (Corning, 2008). Splice loss (Table 3) was acceptable despite destruction of photonic structure over $300 \mu \mathrm{m}$ (Figures 24 and 25), due to guiding of light by doped core. This case was easy, as no special techniques were required besides reduction of fusion power and duration in comparison to SMF splicing. Lower loss was achievable with shorter fusion time, but at expense of reduced splice strength.

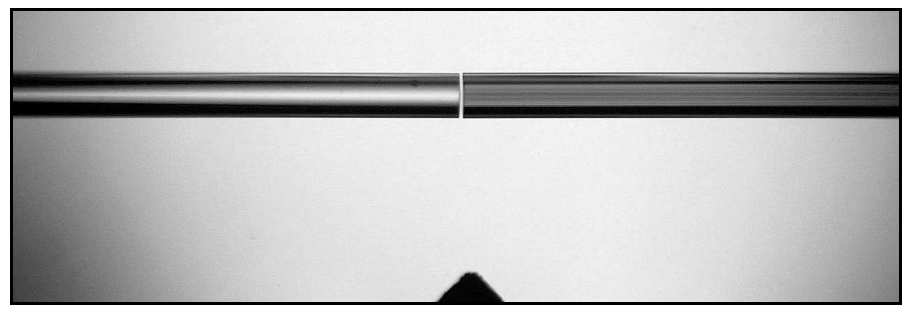

Fig. 24. SMF (left) and PCF (right) cleaved and positioned before fusion.

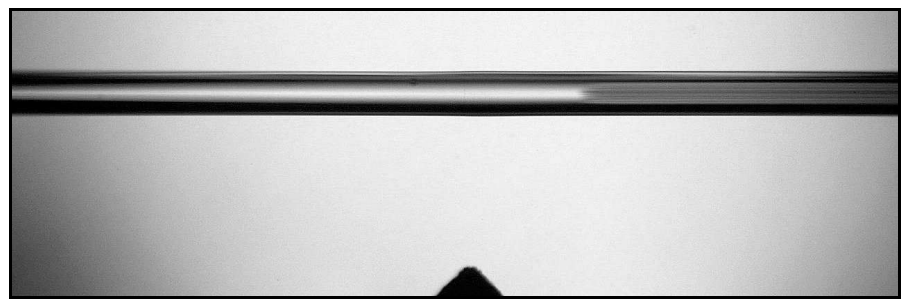

Fig. 25. Fibres fused.

\begin{tabular}{|c|c|c|}
\hline Conditions & Sample loss $(\mathrm{dB})$ & Splice loss $(\mathrm{dB})$ \\
\hline Loss with finished splice No. 1 & 3.19 & (reference) \\
\hline Fibres cleaved and aligned & 4.79 & 2.37 \\
\hline Fibres spliced & 3.77 & 1.25 \\
\hline
\end{tabular}

Table 3. Loss of IPHT 282b4 sample measured during making of splice No. 2 (1558 nm).

\subsubsection{Splicing IPHT 252b5 to SMF (Corning SMF-28)}

This PCF was difficult to splice due to small diameter. Fusion procedure included melting of fiber tips into ball lenses before fusion (Wang et a., 2008). Results depended on accurate fiber movement ("feed") before fusion: too small increased necking (Figures 29-30) and loss. Fiber was $16.08 \mathrm{~m}$ long, with attenuation and loss at $1558 \mathrm{~nm}$ of $58.3 \mathrm{~dB} / \mathrm{km}$ and $0.94 \mathrm{~dB}$, respectively. The SMF was Corning SMF-28. Gap during alignment was $10 \mu \mathrm{m}$, fibre overlap $10 \mu \mathrm{m}$ and axial offset $200 \mu \mathrm{m}$ towards SMF. Splicing machine settings were as follows:

- $\quad$ Splicing (pre-fusion, fusion, annealing): $9 \mathrm{~mA}-3 \mathrm{~s} / 18 \mathrm{~mA}-0.5 \mathrm{~s} / 8.4 \mathrm{~mA}-3 \mathrm{~s}$.

- $\quad$ Melting of fibre tips: $18 \mathrm{~mA}-0.5 \mathrm{~s}$. 
After measuring loss with butt coupling (Figure 26), fibres were melted to form ball lenses (Figures 26-28). Melting of SMF tip was repeated to obtain the required shape. After fusion (Figure 29), the splice was repeatedly heated at the same settings to reduce loss, but without further movement (Figures 29-30). Light transmission was monitored and work terminated after splice loss stopped to significantly decrease any further - see data in Table 4.
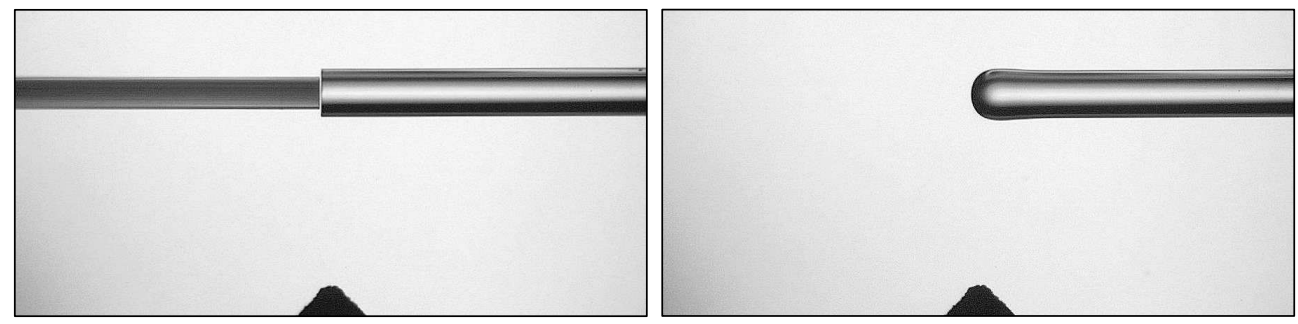

Fig. 26. Left: PCF (left) and SMF (right) aligned. Electrode tip is visible as dark triangle at the bottom of picture. Right: SMF tip melted - Phase 1.
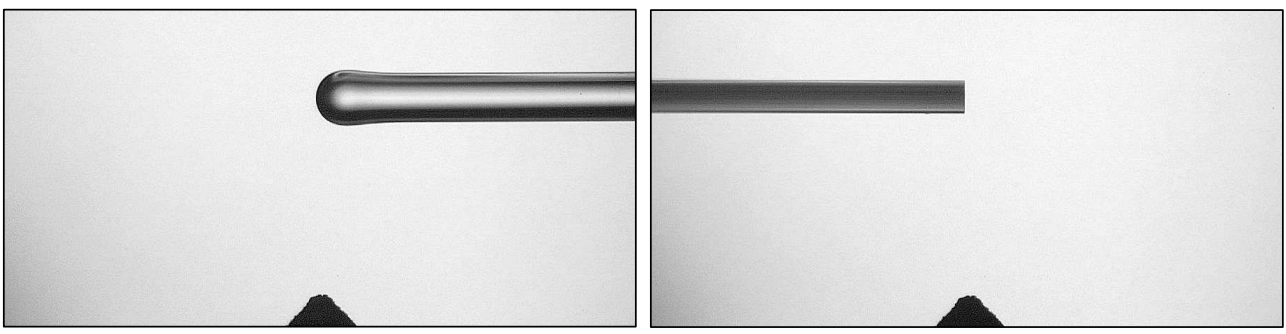

Fig. 27. Left: SMF tip melted - Phase 2. Right: PCF positioned for melting.
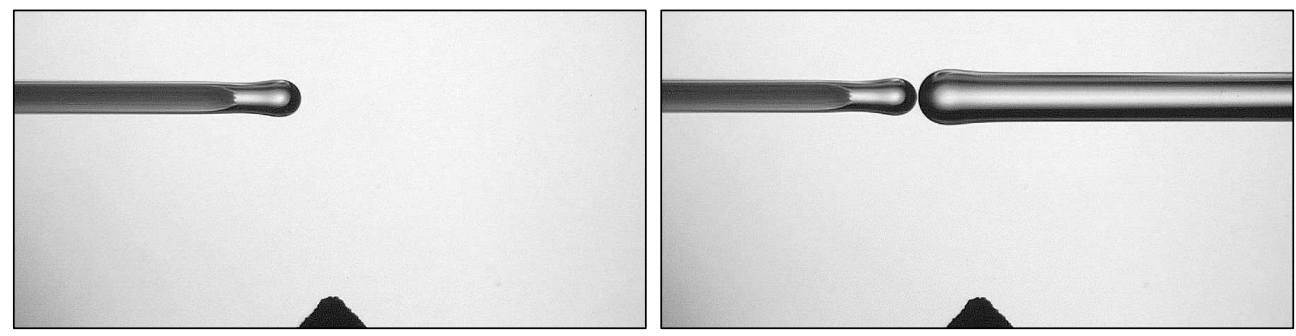

Fig. 28. Left: PCF tip melted. Right: fibres aligned for fusion with axial offset.
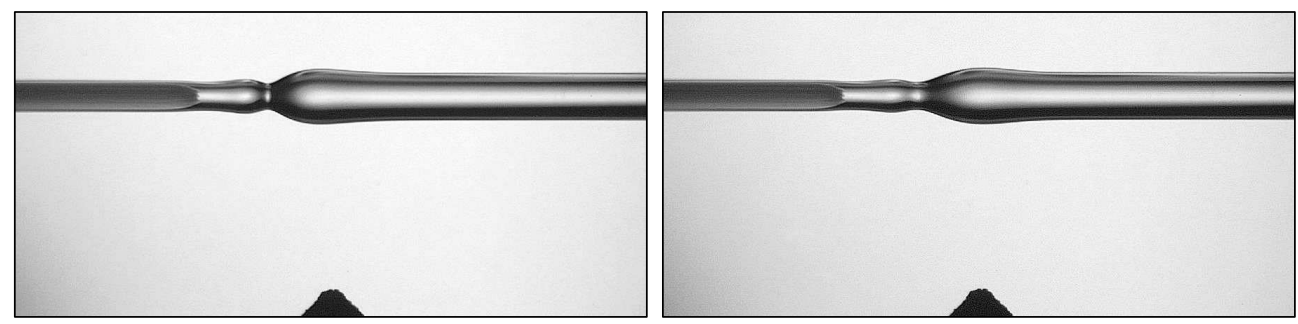

Fig. 29. Left: fibres fused. Right: splice after additional heating No. 1. 

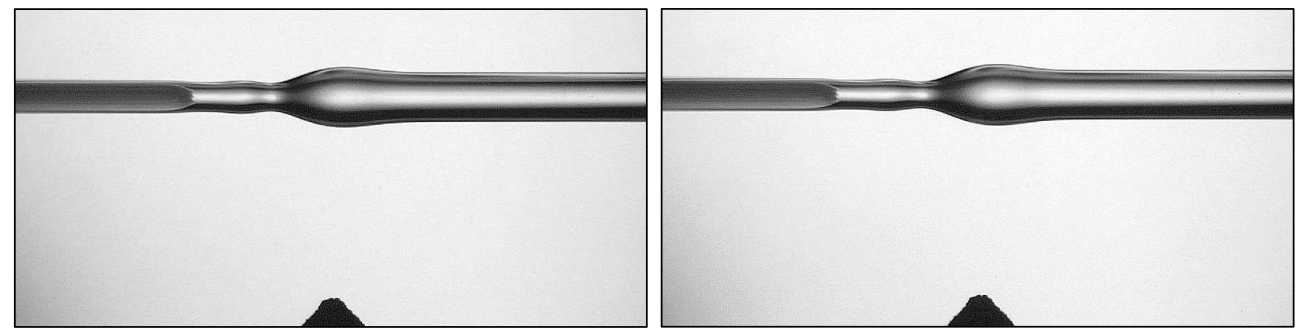

Fig. 30. Splice after additional heating No. 2 (left) and No. 3 (right).

\begin{tabular}{|c|c|c|}
\hline Conditions & Sample loss $(\mathrm{dB})$ & Splice loss (dB) \\
\hline Loss with finished splice 1 & 3.19 & (reference) \\
\hline Fibers cleaved and aligned & 8.98 & 5.79 \\
\hline Lens-tipped fibres aligned & 5.37 & 2.18 \\
\hline Fibres spliced & 4.61 & 1.42 \\
\hline After heating No. 1 & 4.38 & 1.19 \\
\hline After heating No. 2 & 4.28 & 1.09 \\
\hline After heating No. 3 & 4.17 & 0.98 \\
\hline
\end{tabular}

Table 4. Loss of IPHT 252b5 sample measured during making of splice No. 2 (1558 nm).

In contrast to work presented in the preceding section, fusion splicing of small-core, thin PCF to SMF was complicated and time-consuming. However, attempts to fuse the same fibres without pre-forming resulted in very high splice loss (15.5 dB for 2 PCF-SMF splices) and frequent entrapment of small gas bubble in the centre of splice.

\section{Conclusions}

Arc fusion splicing of most microstructured silica-based fibres to SMFs with conventional equipment and tools is possible, with loss acceptable for purposes like PCF characterization.

Unfortunately, splicing procedure must be tailored to each PCF and is labour intensive. In many cases, a trade-off between achieving low loss and high strength of the splice exists.

PCF to PCF splicing is more demanding in term of equipment and work procedures, because of need for rotational alignment of fibres, not available in most fusion splicing machines, and increased length of collapsed holes. The latter problem can be reduced by adopting fusion time shorter than $0.3 \mathrm{~s}$, but at the expense of compromised splice strength.

\section{Acknowledgments}

Most of work presented in this chapter was carried out within COST Action 299 "FIDES". Research at NIT was financially supported by Polish Ministry of Science and Higher Education as special research project COST/39/2007. 


\section{References}

Bang, O. (2010). PCFs, mPOFs and THz fibers. Proc. 2nd Workshop on Specialty Optical Fibers and their Applications (WSOF 2010), ISBN: 978-0-8194-8360-7, Oaxaca City, Mexico, October 13-15, 2010. Available from

http://www.cio.mx/WSOF2010/archivos/Ole\%20Bang.pdf

Borzycki, K., Kobelke, J., Schuster K. \& Wójcik J. (2010). Arc fusion splicing of photonic crystal fibers to standard single mode fibers. Proc. SPIE 7714-38, ISBN 9780819481870, SPIE Photonics Europe 2010, Brussels, Belgium, April 12-16, 2010

Borzycki, K., Kobelke, J., Schuster K. \& Wójcik J. (2010). Optical, thermal and mechanical characterization of photonic crystal fibers: results and comparisons. Proc. SPIE 7714-31, ISBN 978-0-81948-1870, SPIE Photonics Europe 2010, Brussels, Belgium, April 12-16, 2010

Borzycki, K., Kobelke, J., Mergo, P. \& Schuster K. (2011). Challenges in characterization of photonic crystal fibers. Proc. SPIE 8073B-107, ISBN 978-0-81948-663-9, SPIE Optics + Optoelectronics 2011, Prague, Czech Republic, April 18-21, 2011.

Borzycki, K., Kobelke, J., Mergo, P. \& Schuster K. (2011). Characterization of photonic crystal fibres with OTDR. Proc. ICTON 2011, ISBN 978-1-4577-0881-7, paper We.B4.5, Stockholm, Sweden, June 27-29, 2011

Bourliaguet, B., Paré, C., Émond, F., Croteau, A., Proulx, A. \& Vallée, R. (2003). Microstructured fiber splicing. Optics Express, eISSN: 1094-4087, Vol. 11, No. 25, pp. 3412-3417

Corning Inc. (2008). Corning SMF-28e Optical Fiber Product Information. PI1344 (09/2008)

Edvold, B. \& Gruner-Nielsen, L. (1996). New technique for reducing the splice loss to dispersion compensating fiber. Proceedings of ECOC-1996, Vol. 2, pp. 245-248, ISBN 82-423-0418-1, Oslo, Norway, September 15-19, 1996

IEC 60793-2-50 Ed. 3.0: Optical fibres - Part 2-50: Product specifications - Sectional specification for class B single-mode fibres, ISBN 2-8318-9824-2 (05/2008)

ITU-T Recommendation G.652: Characteristics of a single-mode optical fibre and cable (11/2009). Available from http://www.itu.int/rec/T-REC-G.652-200911-I

ITU-T Recommendation G.657: Characteristics of a bending-loss insensitive single-mode optical fibre and cable for the access network (11/2009). Available from http:/ / www.itu.int/rec/T-REC-G.657-200911-I

Law, S.H., Harvey, J.D., Kruhlak, R.J, Song, M., Wu, E., Barton, G.W., van Eijkelenborg, M.A. \& Large, M.C.J. (2006). Cleaving of microstructured polymer optical fibres. Optics Communications, ISSN 00304018, Vol. 258, Issue 2, pp. 193-202

Matthewson, M.J., Kurkjian, C.R. \& Hamblin, J.R. (1997). Acid stripping of fused silica optical fibers without strength degradation. Journal of Lightwave Technology, ISSN 0733-8724, Vol. 15, Issue 3, pp. 490-497

Nakajima, K., Hogari, K., Zhou, J., Tajima, K. \& Sankawa I. (2003). "Hole-Assisted Fiber Design for Small Bending and Splice Losses", IEEE Photonics Technol. Lett., ISSN 1041-1135, Vol. 15, No. 12, pp. 1737-1739

OFS (2008). Fitel S183PMII - A New Standard in the Field for High-End Fusion Splicing Applications (FITEL-S183-PMII-1108)

Schott North America, Inc. (2007). Schott Technical Glasses: Physical and technical properties (11/2007). Available from:

http://www.us.schott.com/english/download/technical_glass_guide_us.pdf 
Schuster, K., Kobelke, J., Grimm, S., Schwuchow, A., Kirchhof, J., Bartelt, H., Gebhardt, A., Leproux, P., Couderc, V. \& Urbanczyk, W. (2007). Microstructured fibers with highly nonlinear materials. Journ. Opt. Quant. Electron., ISSN 0306-8919, Vol. 39, pp. 1057-1069

Shand E.B. (1968). Engineering Glass, Modern Materials Vol. 6, Academic Press, New York

Thapa, R., Knabe, K., Corwin, K. L. \& Washburn, B. R. (2006). Arc fusion splicing of hollowcore photonic bandgap fibers for gas-filled fiber cells. Optics Express, eISSN 10944087, Vol. 14, No. 21, pp. 9576-9583

Vytran (2009). FFS-2000 Filament Fusion Splicing Workstation: An Integrated System for Production and Specialty Fiber Splicing. Available from: http://www.vytran.com/publications/datasheet_ffs_2009.pdf

Wang, Y., Bartelt, H., Brueckner, S., Kobelke, J., Rothhardt, M., Mörl, K., Ecke, W. \& Willsch, R. (2008). Splicing Ge-doped photonic crystal fibers using commercial fusion splicer with default discharge parameters. Optics Express, eISSN 1094-4087, Vol. 16, No. 10, pp. 7258-7263. Available from http://www.opticsinfobase.org/oe/abstract.cfm?URI=oe-16-10-7258

Xiao, L., Demokan, S., Jin, W., Wang, Y. \& Zhao, C. (2007). Fusion Splicing Photonic Crystal Fibers And Conventional Single-Mode Fibers: Microhole Collapse Effect. Journal of Lightwave Technology, ISSN 07338724, Vol. 25, No. 11, pp. 3563-3574

Yablon, A. D. \& Bise R. (2004). Low-Loss High-Strength Microstructured Fiber Fusion Splices Using GRIN Fiber Lenses. Proc. OFC 2004, p. 41, paper MF14, ISBN 1-55752772-5, Optical Fiber Communication Conference 2004, Los Angeles, CA, USA, 2327 Feb. 2004

Yablon A. (2005). Optical Fiber Fusion Splicing, Springer Verlag, ISBN 3-540-23104-8, Berlin Heidelberg - New York 


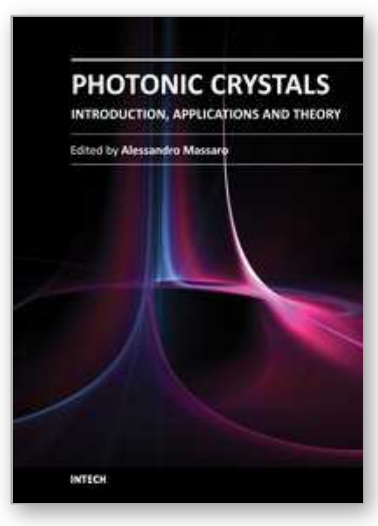

\author{
Photonic Crystals - Introduction, Applications and Theory \\ Edited by Dr. Alessandro Massaro
}

ISBN 978-953-51-0431-5

Hard cover, 344 pages

Publisher InTech

Published online 30, March, 2012

Published in print edition March, 2012

The first volume of the book concerns the introduction of photonic crystals and applications including design and modeling aspects. Photonic crystals are attractive optical materials for controlling and manipulating the flow of light. In particular, photonic crystals are of great interest for both fundamental and applied research, and the two dimensional ones are beginning to find commercial applications such as optical logic devices, micro electro-mechanical systems (MEMS), sensors. The first commercial products involving twodimensionally periodic photonic crystals are already available in the form of photonic-crystal fibers, which use a microscale structure to confine light with radically different characteristics compared to conventional optical fiber for applications in nonlinear devices and guiding wavelengths. The goal of the first volume is to provide an overview about the listed issues.

\title{
How to reference
}

In order to correctly reference this scholarly work, feel free to copy and paste the following:

Krzysztof Borzycki and Kay Schuster (2012). Arc Fusion Splicing of Photonic Crystal Fibres, Photonic Crystals Introduction, Applications and Theory, Dr. Alessandro Massaro (Ed.), ISBN: 978-953-51-0431-5, InTech, Available from: http://www.intechopen.com/books/photonic-crystals-introduction-applications-and-theory/arcfusion-splicing-of-photonic-crystal-fibers

\section{INTECH}

open science | open minds

\author{
InTech Europe \\ University Campus STeP Ri \\ Slavka Krautzeka 83/A \\ 51000 Rijeka, Croatia \\ Phone: +385 (51) 770447 \\ Fax: +385 (51) 686166 \\ www.intechopen.com
}

\author{
InTech China \\ Unit 405, Office Block, Hotel Equatorial Shanghai \\ No.65, Yan An Road (West), Shanghai, 200040, China \\ 中国上海市延安西路65号上海国际贵都大饭店办公楼 405 单元 \\ Phone: +86-21-62489820 \\ Fax: +86-21-62489821
}


(C) 2012 The Author(s). Licensee IntechOpen. This is an open access article distributed under the terms of the Creative Commons Attribution 3.0 License, which permits unrestricted use, distribution, and reproduction in any medium, provided the original work is properly cited. 